\title{
TWO-LEVEL PROMOTION AND ORDERING POLICY IN A SUPPLY CHAIN
}

\author{
Yu-Chung TsaO ${ }^{1,2, *}$, Hui-Ling FAn ${ }^{1}$, Lu-Wen LiaO ${ }^{3}$, \\ Thuy-Linh Vu ${ }^{1,2}$ AND Pei-Ling LeE ${ }^{1,2}$
}

\begin{abstract}
This research develops two models to consider retailer sales promotion and manufacturer trade promotion under demand uncertainty. The objective of the first model is to determine the retailer's optimal promotional effort and order quantity while maximizing the retailer's profit under exogenous trade promotion. The second model extends the first to consider the manufacturer's endogenous trade promotion decisions. For these models, three different trade promotion policies (off-invoice, scan-back, unsold-discount) have been compared to identify the policy that can increase the manufacturer's and the retailer's profits. For the model with exogenous trade promotion, the retailer's promotional effort level, order quantity, and profit are highest under the off-invoice trade promotion policy. With respect to the manufacturer's endogenous trade promotion decisions, the retailer's promotional effort level, order quantity, and profit, and the manufacturer's profit are higher under the off-invoice policy than under the scan-backs policy. When comparing the three different trade promotion policies, we also find that the wholesale price is a key factor that influences a manufacturer's profit. Our research sheds light on the importance of trade promotion policy in supply chain management.
\end{abstract}

Mathematics Subject Classification. 90B05.

Received October 10, 2018. Accepted September 6, 2019.

\section{INTRODUCTION}

In the distribution channel, trade promotion plays an important role to push products to end customers. It allows upstream players to offer downstream players some special price discounts or incentive policies to increase their sales. Trade promotion is currently one of the single best line items for manufacturers and Neilsen has confirmed that they account for almost $60 \%$ of the company's marketing budget [24] for consumer packaged goods (CPG). With trade promotion spending accounting for $15-20 \%$ of sale revenue [3], it is even more critical for companies to consider increasing trade promotion budgets and how to select the trade promotion policies that are best suited to them.

Blattberg and Neslin [2] delineated three types of sales promotions: trade promotion from the manufacturer to the retailer, retailer promotion from the retailer to the consumers, and consumer promotion from the

Keywords. Supply chain management, replenishment, trade promotion, sales promotion, promotional effort.

1 Department of Industrial Management, National Taiwan University of Science and Technology, Taipei, Taiwan (R.O.C).

2 Artificial Intelligence for Operations Management Research Center, National Taiwan University of Science and Technology, Taipei, Taiwan (R.O.C).

3 College of Intelligence, National Taichung University of Science and Technology, Taichung, Taiwan (R.O.C).

* Corresponding author: yctsao@mail.ntust.edu.tw 
manufacturer to the consumers (manufacturer promotion). As we see in Table 1, there are many researches which have considered trade promotion $[1,13,16,28,29,32]$ or retailer promotion $[17,18,25,30]$ individually. In a different way, Yang et al. [34] consider two types of sales promotion: manufacturer's promotion (the manufacturer can promote via a direct channel) and retailer's promotion (the retailer can promote via a retail channel) independently. In practice, these two or three types of sales promotion could exist at the same time in the one supply chain. During holidays, many stores provide discounts on their products or hold sales activities to effectively increase consumer demand. Retailers need to adopt an appropriate ordering policy to meet the rising demand. Manufacturers provide a discount based on the retailer's ordering policy. For products such as sports goods, necessaries, clothes, and other articles of daily use, promotion indeed stimulates heavy demand. However, two-level promotion is not only effective for short-term sales promotion activities, such as New Year and Christmas sales but is also feasible in the long term. For example, some well-known brands such as Adidas, Nike, and Samsung use trade allowance to promote brand awareness and advertise their latest products/services. Consequently, the design of two-level promotions to ensure the optimal profit for all players in the supply chain is a practical and important issue. However, in the literature, there is a lack of studies that consider two-level promotion (see Sect. 2); studies only focus on one method of trade promotion [9,14,33]. To extend the literature, this research considers two-level promotion (manufacturer's trade promotion and retailer's sale promotion) while providing a comparison of three common methods of trade promotion to help managers determine the most suitable policy for their supply chain.

In our model, the three methods of trade promotion in which the manufacturers offer a discount as a fixed amount or percentage of the original to increase the sales margin: off-invoice, scan-back, and unsold-discount trade promotion are considered. In the case of off-invoice promotion, the manufacturer provides some discounts based on the retailer's order quantity. However, the manufacturer cannot exert control over retailers to fully pass on the trade promotion discount to end consumers. This leads to a principal-agent problem, which is defined in game theory as the factor motivating one decision-maker to act on behalf of another [13]. Scan-back trade promotion is created as a solution to the principal-agent problem by allowing the manufacturer to monitor end sales to customers using information technology. The manufacturer provides the discount based on the exact number of sales the retailer makes. However, whether the retailer is willing to accept the scan-back trade promotion is another issue. What happens if the number of inventories increases? Another trade promotion is considered, an unsold-discount trade promotion, wherein the discount obtained from the manufacturer depends on the retailer's unmarketable quantities. This trade promotion policy is different from the aforementioned two policies in that the manufacturer offers the retailers a lower price for unsold products than the price of goods sold. Therefore, the retailer can lower the unit retail price, which, in turn, increases the product demand from consumers.

This study contributes to literature as follows. First, we build the two-level promotion models with a single manufacturer and a single retailer under demand uncertainty. A manufacturer offers the trade promotion policies to a retailer while the retailer conducts sales promotion to induce greater demand from customers. Second, three different trade promotion policies (off-invoice, scan back, and unsold-discount) are compared in our models. The aim is to identify the trade promotion policy that can increase the manufacturer's and the retailer's profits. To best our knowledge, this is the first study which has discussed the two-level promotion and compared three different trade promotion policies. Furthermore, two supply chain models with exogenous and endogenous trade promotions are considered. In the first model, the retailer determines the optimal order quantity and promotional effort effect level to maximize its own profit. The second model extends the first to consider the manufacturer's endogenous trade promotion decisions. Finally, we also run numerical examples to obtain some managerial insights that could be used as a reference for companies and managers.

The rest of the paper is organized as follows. The next section presents a review of the literature. In Section 3 , a basic model for two-level promotion with demand based on promotional effort is developed. The basic model is extended to consider the manufacturer's decision variable in Section 4. Section 5 uses numerical examples to examine how decision variables perform when optimal trade promotion discount is achieved. Finally, in Section 6 , we present our conclusion in detail and provide some suggestions and comments for future research. 
TABLE 1. Comparisons of previous works.

\begin{tabular}{|c|c|c|c|c|c|c|}
\hline & $\begin{array}{l}\text { Trade } \\
\text { promotion }\end{array}$ & $\begin{array}{l}\text { Retailer } \\
\text { promotion }\end{array}$ & $\begin{array}{l}\text { Manufacturer } \\
\text { promotion }\end{array}$ & $\begin{array}{l}\text { Two-level } \\
\text { promotion }\end{array}$ & $\begin{array}{l}\text { N. of promotion } \\
\text { policy }\end{array}$ & $\begin{array}{l}\text { Demand } \\
\text { pattern }\end{array}$ \\
\hline Lal and Villas-Boas [14] & $\mathrm{x}$ & $\mathrm{x}$ & & $\mathrm{x}$ & 1 & $\mathrm{~N} / \mathrm{I}$ \\
\hline Lu and Moorthy [18] & & $\mathrm{x}$ & & & 2 & $\mathrm{~N} / \mathrm{I}$ \\
\hline Kurata and Yue [13] & $\mathrm{x}$ & & & & 1 & $\begin{array}{l}\text { Promotional budget } \\
\text { dependent }\end{array}$ \\
\hline Tsao and Sheen [30] & & $\mathrm{x}$ & & & 1 & $\begin{array}{l}\text { promotional } \\
\text { effort-induced demand }\end{array}$ \\
\hline $\mathrm{Su}$ and Geunes [28] & $\mathrm{x}$ & & & & 1 & $\begin{array}{l}\text { Price discount, outcome } \\
\text { dependent }\end{array}$ \\
\hline Pal et al. $[22]$ & & $\mathrm{x}$ & & & 1 & $\begin{array}{l}\text { Price, product qual- } \\
\text { ity, promotional effort } \\
\text { dependent }\end{array}$ \\
\hline Yang et al. [33] & $\mathrm{x}$ & $\mathrm{x}$ & & & 1 & $\begin{array}{l}\text { Random variable, pro- } \\
\text { motional efforts, rebate } \\
\text { face dependent }\end{array}$ \\
\hline Sana $[25]$ & & $\mathrm{x}$ & & & 1 & $\begin{array}{l}\text { Random variable and } \\
\text { sales teams' initiatives } \\
\text { dependent }\end{array}$ \\
\hline Tsao and $\mathrm{Lu}[29]$ & $\mathrm{x}$ & & & & 4 & $\begin{array}{l}\text { Promotional cost } \\
\text { dependent }\end{array}$ \\
\hline $\operatorname{Lin}[16]$ & $\mathrm{x}$ & & & & 1 & $\begin{array}{l}\text { Promotional cost depen- } \\
\text { dent }\end{array}$ \\
\hline Bai et al. [1] & $\mathrm{x}$ & & & & 2 & $\begin{array}{l}\text { Price, time, promotional } \\
\text { effort dependent }\end{array}$ \\
\hline Wu et al. [32] & $\mathrm{x}$ & & & & 3 & Price dependent \\
\hline Fang and Yuan [6] & $\mathrm{x}$ & & & & 1 & Time dependent \\
\hline Liu et al. $[17]$ & & $\mathrm{x}$ & & & 2 & $\begin{array}{l}\text { Quality and sales effort } \\
\text { dependent }\end{array}$ \\
\hline Yang et al. [34] & & $\mathrm{x}$ & $\mathrm{x}$ & & & Price dependent \\
\hline Pakhira et al. [23] & $\mathrm{x}$ & & & & 1 & $\begin{array}{l}\text { Promotional cost and } \\
\text { trade credit dependent }\end{array}$ \\
\hline Nouri et al. [19] & & $\mathrm{x}$ & & & 1 & $\begin{array}{l}\text { Promotional \& innova- } \\
\text { tion efforts dependent }\end{array}$ \\
\hline This study & $\mathrm{x}$ & $\mathrm{x}$ & & $\mathrm{x}$ & 3 & $\begin{array}{l}\text { Promotional efforts } \\
\text { dependent }\end{array}$ \\
\hline
\end{tabular}

\section{LiterATURE REVIEW}

\subsection{Sales promotion}

Sales promotions play vital role in creating incentives for customers to buy products more quickly and make larger purchases. There are different forms of sales promotion for retailers facing varying competitive environments with different types of products, such as price discount [7], coupons [31], loyalty discounts [21], displays, rebate [10], promotional packaging, TV commercials, and so on. Sigue [27] argued that manufacturers are willing to support retailer promotions because it can significantly increase future sales through side-payment mechanisms such as promotional allowances and cooperative advertising arrangements.

Most of the existing literature on retailer sales promotion only considers single-level promotion. For example, $\mathrm{Lu}$ and Moorthy [18] demonstrated the difference between two promotional vehicles for retailers: coupons and rebates. Osman et al. [20] examined the impacts of sales promotion on buying behavior and identified ways to help the marketer devise suitable strategies to increase sales. Tsao and Sheen [30] considered a two-echelon multiple-retailer distribution channel in addition to retailers' promotional efforts and the sales learning curve. 
Whatever the motivation for sales promotion, its aim is to stimulate sales. Therefore, to evaluate their profitability, retailers must take promotional effort costs into account. In our research, we consider the cost and impact of sales promotion reflected in our demand restrictions formula. The market demand is assumed to be dependent on the promotional effort of the retailer, as in Pal et al. [22], Sana [25], Nouri et al. [19] and Liu et al. [17].

\subsection{Trade promotion}

The two most common methods of trade promotion are off-invoice and scan-back trade promotion. There have been a number of studies that specifically focus on the differences between these two methods. For example, Kurata and Yue [13] explored a new way for manufacturers and retailers in a two-stage fashion supply chain to shift from a traditional trade promotion method (off-invoice) to a new method (scan-back) enabled by information sharing. Su and Geunes [28] developed a bi-level model of a decentralized two-stage supply chain in which the manufacturer's pricing decision (trade promotion levels) and the retailer's operations (order value, inventory levels, and transshipment quantities) can be determined simultaneously. Yuan et al. [35] proposed an analytical model and implemented market experiments to examine optimal channel member behavior regarding trade promotion decisions. However, they only considered upstream promotion.

Trade promotion has been used as a tool by manufacturers to distinguish their sales from that of retailers [4]. Some studies have been conducted to examine the benefit for both manufacturers and retailers. For example, research by Dreze and Bell [5] focused on scan-back trade promotion and demonstrates that a manufacturer can devise a "redesigned scan-back" agreement that makes him/her strictly better off and the retailer slightly better off. Kurata and Yue [13] added the buyback contract in their supply chain model and found that the manufacturer and the retailer can achieve a win-win solution to maximize their profits if the manufacturer uses scan-back trade promotion accompanied by the buyback contract. Recently, Lin [16] considered the price promotion in a supply chain comprising one manufacturer and one retailer who takes into account the reference price effects of consumers He/She assumed that the demand function is linear and includes reference price effects. Bai et al. [1] developed a two-echelon sustainable supply chain system for deteriorating items under carbon capand-trade regulation and compare these two contracts: revenue and promotional cost-sharing contract and a two-part tariff contract analytically and numerically. Wu et al. [32] analyzed trade promotions under demand disruption (demand uncertainty and limited capacity). Specifically, off-invoice, scan-back, and revenue-sharing trade promotions were examined. Pakhira et al. [23] considered if the supplier shares a part of the promotional cost then the channel profit as well as individual profits increases. Fang and Yuan [6] focused on manufacturer promotion in which manufacturers usually launch a time-sensitivity promotional mechanism that the earlier you order, the cheaper the wholesale price will be in advance of the selling season. These two supply chain contracts: time-sensitive wholesale price contract and time-sensitive revenue-sharing contract were constructed to reach supply chain coordination and improve supply chain performance.

\subsection{Unsold-discount}

In our research, we also consider the third trade promotion method, unsold-discount trade promotion. From the manufacturer's point of view, it is natural that the extent of discount can influence the retailer's order quantity. To support the retailer, the manufacturer offers discounts to retailers when there is unsold inventory. To the best of our knowledge, the literature on the application of unsold-discount trade promotion in operations management is very limited, and only a few studies on concepts similar to this trade promotion policy exist. For instance, Hahn et al. [8] found that a retailer dealt with perishable goods with a finite life when manufacturers allowed retailers to not return the unsold perishable goods and offered discounts on the wholesale price. Shen and $\mathrm{Li}[26]$ examined the influence of returning unsold products in a retail outsourcing fashion supply chain. They found that a low logistic cost for returning products may not be beneficial to supply chain sustainability. Tsao and $\mathrm{Lu}$ [29] compared four trade promotions, off-invoice, scan-back, unsold-discount and target rebate, in a manufacturer-retailer supply chain in which the manufacturer provides trade promotions to the retailer. This 
study extends Tsao and $\mathrm{Lu}[29]$ to consider the two-level promotion in which the retailer also offers the sales promotion to its customers.

\subsection{Two-level promotion}

There are a few studies in the literature that have discussed two-level promotion. For example, Lal and Villas-Boas [14] studied the interaction of two-level promotion between two manufacturer brands and two competing retailers. They showed that retailers sometimes offer the same discount on different products; however, they generally provide a relatively small discount on a brand supported by a relatively large trade promotion. Jorgensen et al. [9] formulated a supply chain in which a manufacturer advertises to build its national brand image and a retailer promotes the brand locally to increase sales volume; however, these efforts may be harmful to the brand image. They considered the specific case of a cooperative program in which the manufacturer pays part of the costs incurred by the retailer in promoting the brand. Yang et al. [33] used a newsvendor modelling framework involving two-level promotion wherein the manufacturer provides mail-in rebates directly to consumers, while the retailer exerts promotional effort to further stimulate consumer demand.

To sum up, the existing literature on promotional mechanism always considers the single level of promotion with general assumption of promotion types. To the best of the authors' knowledge, the two level of promotion analysis has not been popular in the literature (Tab. 1). Therefore, this study studies the two models of two-level promotions: trade promotion from the manufacturer to the retailer and retailer promotion from the retailer to the consumers with three different types of promotional mechanism (off-invoice, scan-back, and unsold-discount).

\section{Exogenous trade PROMOTION}

This paper considers a newsvendor model in which the manufacturer sells products to a retailer with trade promotion, and the retailer sells the products to customers with sales promotion under demand uncertainty. Let $\rho$ be the retailer's promotional effort level, $Q$ be the quantity ordered by the retailer from the manufacturer, and $D$ be the stochastic demand in our manufacturer-retailer supply chain. The product's retail price $P$, wholesale price $W$, and production cost $C$ are fixed per unit.

In this section, we focus on the retailer's decisions regarding promotional effort to stimulate consumer demand and increase order quantity from the manufacturer to maximize his/her profit. In Section 3, we build the basic model under exogenous trade promotion discount.

\subsection{Notations and assumptions}

The following notations and assumptions are used in the model (Tab. 2).

The mathematical model in this study is based on the following assumptions:

(1) We consider a problem involving a single product and no shortage costs if demand cannot be met. In the standard newsvendor problem, no shortage cost is assumed if the purchased quantity is less than the demand [15]. Because the company only has one chance to order the products (one period to sell the products) and the customers lost anymore when shortages happen. Those products that only be sold in one single period could be examples for no shortage cost.

(2) To generate positive profit, the manufacturer's and retailer's parameters must satisfy the condition, $P>$ $W>C$, that is, the retail price of a product must be greater than the wholesale price, and the wholesale price must greater than the product cost.

(3) The retailer's promotional efforts can increase consumer demand, and hence, have a positive impact on demand. We assume that the retailer faces a stochastic demand function [35] presented below:

$$
D=f(\rho)+U,
$$

where $f(\rho)=\rho \xi$ is a deterministic function of the promotional effort level with $\xi>0$, and $U$ is a uniform distribution of $[-\rho \xi, \rho \xi]$. 
TABLE 2. Table of symbols.

\begin{tabular}{ll}
\hline \hline & Definitions \\
\hline Decision variables & \\
$\rho_{i}$ & Promotional effort level in the off-invoice $(i=O)$ case, scan-back $(i=S)$ case, or unsold-discounted \\
& $(i=B)$ case \\
$Q_{i}$ & Order quantitiy from a retailer to a manufacturer in the off-invoice $(i=O)$ case, scan-back $(i=S)$ case, \\
& or unsold-discounted $(i=B)$ case \\
Parameters \\
$\xi$ & Basic demand (without promotion effort) \\
$D$ & Demand with promotion effort \\
$C$ & Manufacturer's unit production cost \\
$W$ & Manufacturer's wholesales price \\
$P$ & Retail price \\
$\Pi_{M_{i}}$ & Manufacturer's expected profit in the off-invoice $(i=O)$ case, scan-back $(i=S)$ case, or unsold-discounted \\
$\Pi_{R_{i}}$ & Retailer's expected profit in the off-invoice $(i=O)$ case, scan-back $(i=S)$ case, or unsold-discounted \\
$\alpha$ & Off-invoice unit discount \\
$\beta$ & Scan-back unit discount \\
$B$ & Unit Unsold-discount
\end{tabular}

(4) The retailer conducts sales promotion to induce greater demand. The promotional effort exerted by the retailer after demand $\xi$ is observed [11]. The cost of the promotional effort is given by $C(\rho, \xi)=K(\rho-1) \xi$, where $C(\rho, \xi)$ is a convex, increasing, and continuously differentiable with respect to $\rho$ for any $\rho \geq 1$, and all $K>0$ are constants. Further, $C(1, \xi)=0$, and $C(\rho, \xi)$ is continuous in $\xi$ for any $\rho \geq 1$. Higher values of $K$ imply greater difficulty in attracting consumers. However, in our research, we assume $K=1$, and this effort cost is belonging to the retailer.

(5) In the reasonable situation, the range of trade promotion discounts cannot be lower than zero and cannot exceed the wholesale price.

\subsection{Mathematical model}

The first step of our analysis focuses on building basic model. To distinguish between the three different types of trade promotion discount, we use $\alpha(\beta, B)$ to represent the per-unit off-invoice (scan-back, unsold-discount) discount and subscript $O(S, B)$ to represent the parameters in a supply chain where off-invoice (scan-back, unsold-discount) policy is offered.

\subsubsection{Off-invoice discount}

Under the off-invoice policy, the manufacturer offers discount $\alpha$ to the retailer, and the discount is subtracted from the initial invoice on all the units ordered. Therefore, the effective wholesale price to the retailer becomes $W-\alpha$. The profit function is formulated as follows.

The retailer's expected profit $\left(\Pi_{R_{O}}\right)$ :

$$
\begin{aligned}
\Pi_{R_{O}} & =P \int_{0}^{Q_{O}} \frac{t \mathrm{~d} t}{2 \rho_{O} \xi}+P Q_{O} \int_{Q_{O}}^{2 \rho_{O} \xi} \frac{\mathrm{d} t}{2 \rho_{O} \xi}-Q_{O}(W-\alpha)-\left(\rho_{O}-1\right)^{2} \xi \\
& =(P-W+\alpha) Q_{O}-\frac{P Q_{O}^{2}}{4 \rho_{O} \xi}-\left(\rho_{O}-1\right)^{2} \xi .
\end{aligned}
$$


The first term in the retailer's expected profit is the retailer's revenue when the retailer has enough goods/inventory for consumers to buy. The second term is the retailer's expected revenue when the retailer has no extra good/inventory to satisfy consumer demand if the order quantity is smaller than the demand. The last term is the cost of promotional effort, which we define in our assumptions. We determine the optimal order quantity and promotional effort level by solving the following first-order condition:

$$
\begin{aligned}
\frac{\partial \Pi_{R_{O}}}{\partial Q_{O}} & =(P-W+\alpha)-\frac{P_{O} Q_{O}}{2 \rho_{O} \xi}=0 \Rightarrow Q_{O}=\frac{2(P-W+\alpha) \rho_{O} \xi}{P}, \\
\frac{\partial \Pi_{R_{O}}}{\partial \rho_{O}} & =\frac{P_{O} Q_{O}^{2}}{4 \rho_{O}^{2} \xi}-2\left(\rho_{O}-1\right) \xi=0 \Rightarrow Q_{O}=2 \rho_{O} \xi \sqrt{\frac{2\left(\rho_{O}-1\right)}{P}} .
\end{aligned}
$$

Solving equations (3.2) and (3.3) simultaneously to obtain the optimal order quantity and promotional effort level.

$$
\rho_{O}^{*}=1+\frac{(P-W+\alpha)^{2}}{2 P}
$$

and

$$
Q_{O}^{*}=\frac{2 \xi(P-W+\alpha)}{P}\left(1+\frac{(P-W+\alpha)^{2}}{2 P}\right)=\frac{(P-W+\alpha)\left((P-W+\alpha)^{2}+2 P\right) \xi}{P^{2}}
$$

The manufacturer's profit can be written as

$$
\max \Pi_{M_{O}}=\max \left[(W-C-\alpha) Q_{O}\right],
$$

where $\Pi_{M_{O}}$ is the manufacturer's profit under the off-invoice policy.

\subsubsection{Scan-back discount}

In the case of scan-back policy, the manufacturer gives the retailer discount for each unit sold by the retailer to the end consumer. This means the manufacturer offer a per-unit discount $\beta$ to the retailer for each unit sold to consumers. The retailer's profit can be formulated as

$$
\begin{aligned}
\Pi_{R_{S}} & =(P+\beta) \int_{0}^{Q_{S}} \frac{t \mathrm{~d} t}{2 \rho_{S} \xi}+(P+\beta) Q_{S} \int_{Q_{S}}^{2 \rho_{S} \xi} \frac{\mathrm{d} t}{2 \rho_{S} \xi}-Q_{S} W_{S}-\left(\rho_{S}-1\right)^{2} \xi \\
& =(P+\beta-W) Q_{S}-\frac{(P+\beta) Q_{S}^{2}}{4 \rho_{S} \xi}-\left(\rho_{S}-1\right)^{2} \xi .
\end{aligned}
$$

Similar to the off-invoice policy, we take the first-order condition with respect to order quantity and promotional effort level:

$$
\begin{aligned}
& \frac{\partial \Pi_{R_{S}}}{\partial Q_{S}}=(P+\beta-W)-\frac{\left(P_{S}+\beta\right) Q_{S}}{2 \rho_{S} \xi}=0 \Rightarrow Q_{S}=\frac{2(P+\beta-W) \rho_{S} \xi}{(P+\beta)} \\
& \frac{\partial \Pi_{R_{S}}}{\partial \rho_{S}}=\frac{(P+\beta) Q_{S}^{2}}{4 \rho_{S}^{2} \xi}-2\left(\rho_{S}-1\right) \xi=0 \Rightarrow Q_{S}=2 \rho_{S} \xi \sqrt{\frac{2\left(\rho_{S}-1\right)}{P+\beta}}
\end{aligned}
$$

Solving equations (3.8) and (3.9) simultaneously to obtain the optimal order quantity and promotional effort level under the scan-back policy.

$$
\rho_{s}^{*}=1+\frac{(P+\beta-W)^{2}}{2(P+\beta)}
$$


and

$$
Q_{S}^{*}=\frac{2 \xi(P+\beta-W)}{(P+\beta)}\left(1+\frac{(P+\beta-W)^{2}}{2(P+\beta)}\right)=\frac{(P+\beta-W)\left((P+\beta-W)^{2}+2(P+\beta)\right) \xi}{(P+\beta)^{2}} .
$$

Under the scan-back policy, the manufacturer's profit can be written as

$$
\begin{aligned}
\max \Pi_{M_{S}} & =\max \left[Q_{S}(W-C)-\beta \int_{0}^{Q_{S}} \frac{t \mathrm{~d} t}{2 \rho_{S} \xi}-\beta Q_{S} \int_{Q_{S}}^{2 \rho_{s} \xi} \frac{\mathrm{d} t}{2 \rho_{S} \xi}\right] \\
& =Q_{S}(W-C)-\beta\left(Q_{S}-\frac{Q_{S}^{2}}{4 \rho_{S} \xi}\right),
\end{aligned}
$$

where $\Pi_{M_{S}}$ is the manufacturer's profit.

\subsubsection{Unsold discount}

The third type of trade promotion is unsold-discount policy. Under demand uncertainty, the manufacturer's aim is to increase the retailer's order quantity; thus, the manufacturer provides discount for the retailer's unsold inventory. Unlike scan-back policy, unsold-discount policy involves a per-unit discount from the manufacturer to the retailer for each unsold unit. In other words, the manufacturer gives the retailer discounts based on the amount of unsold inventory. Therefore, the retailer's profit $\left(\Pi_{R_{B}}\right)$ can be written as

$$
\begin{aligned}
\Pi_{R_{B}} & =P \int_{0}^{Q_{B}} \frac{t \mathrm{~d} t}{2 \rho_{B} \xi}+P Q_{B} \int_{Q_{B}}^{2 \rho_{B} \xi} \frac{\mathrm{d} t}{2 \rho_{B} \xi}+B \int_{0}^{Q_{B}} \frac{Q_{B}-t}{2 \rho_{B} \xi} \mathrm{d} t-Q_{B} W-\left(\rho_{B}-1\right)^{2} \xi \\
& =(P-W) Q_{B}-\frac{(P-B) Q_{B}^{2}}{4 \rho_{B} \xi}-\left(\rho_{B}-1\right)^{2} \xi .
\end{aligned}
$$

The third term in the retailer's profit function represents the retailer's revenue from the manufacturer when the demand from the end consumers is less than the order quantity.

Similar to the first two cases, we take the first-order condition with respect to order quantity and promotional effort level:

$$
\begin{aligned}
& \frac{\partial \Pi_{R_{B}}}{\partial Q_{B}}=P_{B}-W_{B}-\frac{Q_{B}(P-B)}{2 \rho_{B} \xi}=0 \Rightarrow Q_{B}=\frac{2 \rho_{B} \xi(P-W)}{(P-B)}, \\
& \frac{\partial \Pi_{R_{B}}}{\partial \rho_{B}}=\frac{Q_{B}^{2}(P-B)}{4 \rho_{B}^{2} \xi}-2\left(\rho_{B}-1\right) \xi=0 \Rightarrow Q_{B}=2 \rho_{B} \xi \sqrt{\frac{2\left(\rho_{B}-1\right)}{(P-B)}} .
\end{aligned}
$$

Next, we equate (3.14) and (3.15) to get the optimal order quantity and promotional effort level. We find that

$$
\rho_{B}^{*}=1+\frac{(P-W)^{2}}{2(P-B)}
$$

and

$$
Q_{B}^{*}=\frac{2 \xi(P-W)}{(P-B)}\left(1+\frac{(P-W)^{2}}{2(P-B)}\right)=\frac{(P-W)\left((P-W)^{2}+2(P-B)\right) \xi}{(P-B)^{2}} .
$$

Under the unsold-discount policy, the manufacturer's profit can be written as

$$
\max \Pi_{M_{B}}=\max \left[(W-C) Q_{B}-B \int_{0}^{Q_{B}} \frac{Q_{B}-t}{2 \rho_{B} \xi} \mathrm{d} t\right]=Q_{B}(W-C)-\frac{B Q_{B}^{2}}{4 \rho_{B} \xi} .
$$


From the above fundamental model, it is obvious that when trade promotion budgets are zero $(\alpha=\beta=$ $B=0$ ), the retailer's promotional effort level, order quantity, and profit, and the manufacturer's profit under all the three trade promotion policies are the same $\left(\rho_{o}^{*}=\rho_{s}^{*}=\rho_{B}^{*}, Q_{o}^{*}=Q_{s}^{*}=Q_{B}^{*}, \Pi_{R_{O}}^{*}=\Pi_{R_{S}}^{*}=\Pi_{R_{B}}^{*}\right.$ and $\Pi_{M_{O}}^{*}=\Pi_{M_{S}}^{*}=\Pi_{M_{B}}^{*}$ ). In the next section, we derive propositions regarding off-invoice, scan-back and unsold-discount policies under exogenous trade promotion.

\subsection{Comparisons}

Based on the basic model, we compare the retailer's promotional effort level, order quantity, and channel member profits given the same trade promotion discount.

We first compare promotional efforts considering that each of the three trade promotion policies is offered separately. Proposition 3.1 has been stated below:

Proposition 3.1. Given the same trade promotion discount, the retailer takes the maximum promotional effort in the case of off-invoice policy and takes the minimum promotional effort in the case of unsold-discount policy, that is, $\rho_{o}^{*}>\rho_{s}^{*}>\rho_{B}^{*}$.

See Appendix A for proof.

When the manufacturer offers a trade promotion discount, the retailer's promotional effort level is the highest in the case of off-invoice policy. By definition, when trade promotion budget is allocated to off-invoice policy, retailers receive discounts on all the units ordered. Even when the realized demand is unexpectedly low, retailers can still sell the products by making more promotional efforts because of the discount they received from the manufacturers. Under unsold-discount trade promotion, retailers receive discounts on the unsold units. Therefore, retailers do not make much promotional effort to sell the products because the manufacturer offers discount only on unsold products. Therefore, if we compare off-invoice trade promotion and scan-back trade promotion, retailers would prefer to take the least promotional effort when trade promotion is offered in the unsold-discount format.

Considering uncertain consumer demand, we compare order quantities with each of the three trade promotion policies offered separately. Proposition 3.2 has been stated below:

Proposition 3.2. Considering uncertain consumer demand, a retailer's order quantity is the highest in the case of off-invoice policy compared to the other two trade promotion policies given the same amount of trade promotion discount.

See Appendix A for proof.

The trade promotion discount provided by the manufacturer influences the retailer's ordering policy. Compared to off-invoice trade promotion, retailers would prefer to order a smaller quantity of products under the scan-back policy because when retailers face unexpectedly low demand, it is difficult for them to sell all the order quantity. Moreover, under the unsold-discount policy, retailers would order a smaller quantity than under the off-invoice policy. Because the exogenous trade promotion discount is the same, with unsold-discount trade promotion, retailers can get the maximum revenue from manufacturers only when the products are not sold to the consumers. Therefore, retailers order the maximum quantity under the off-invoice policy compared to the other two trade promotion policies.

Customer demand directly influences retailer profit. In our model, the retailer uses sales promotion as an incentive to boost sales. Sales promotion not only increases the retailer's revenue but also allows the retailer to order a greater quantity from the manufacturer. Considering uncertain consumer demand, we compare the retailer's profit when the three trade promotion policies are offered separately. Proposition 3.3 has been stated below:

Proposition 3.3. Considering uncertain consumer demand, the retailer's profit is the maximum in the case of off-invoice policy compared to the other two trade promotion policies given the same amount of trade promotion discount. 
See Appendix A for proof.

As the exogenous level of trade promotion discount increases the retailer's profits also increase (i.e., $\left.\frac{\mathrm{d} \Pi_{R_{O}}^{*}}{\mathrm{~d} \alpha}>0 ; \frac{\mathrm{d} \Pi_{R_{S}}^{*}}{\mathrm{~d} \beta}>0 ; \frac{\mathrm{d} \Pi_{R_{B}}^{*}}{\mathrm{~d} B}>0\right)$. Trade promotion can indeed increase the retailer's profit. More specifically when the manufacturer provides off-invoice discount to the retailer, the retailer can get the maximum profit by getting the maximum trade promotion level from the manufacturer. Thus to maximize profits the retailer will choose to employ off-invoice policy rather than scan-back or unsold-discount policy

In our research, trade promotions play a key role in determining manufacturer profits. We compare the manufacturer's profit given the same trade promotion discount when the three trade promotion policies are offered separately. First, we compare the manufacturer's profit in the off-invoice case and scan-back case by taking the difference in profit. From equation (3.6), we know that manufacturer profit in the off-invoice case is $\Pi_{M_{O}}^{*}=\left[(W-C-\alpha) Q_{O}^{*}\right]$. From equation (3.5), we can replace $Q_{O}^{*}$ with $\frac{(P-W+\alpha)\left((P-W+\alpha)^{2}+2 P\right) \xi}{P^{2}}$ to derive

$$
\Pi_{M_{O}}^{*}=\frac{(W-C-\alpha)(P-W+\alpha)\left((P-W+\alpha)^{2}+2 P\right) \xi}{P^{2}} .
$$

Similarly, from equation (3.12), we can simplify manufacturer profit in the scan-back case as $\Pi_{M_{S}}^{*}=$ $\left(W-C-\beta\left(1-\frac{Q_{S}^{*}}{4 \rho_{S}^{*} \xi}\right)\right) Q_{S}^{*}$. Using equations (3.10) and (3.11), we replace $\rho_{S}^{*}$ with $\rho_{s}^{*}=1+\frac{(P+\beta-W)^{2}}{2(P+\beta)}$ and $Q_{S}^{*}$ with $Q_{S}^{*}=\frac{(P+\beta-W)\left((P+\beta-W)^{2}+2(P+\beta)\right) \xi}{(P+\beta)^{2}}$ to derive

$$
\Pi_{M_{S}}^{*}=\frac{((P-W+\beta) \beta+2(P+\beta)(W-C-\beta))(P-W+\beta)\left((P-W+\beta)^{2}+2(P+\beta)\right) \xi}{2(P+\beta)^{3}} .
$$

Given the same amount of trade promotion discount in both the cases $(\alpha=\beta)$, the difference is $\frac{A \alpha\left(2(P+\alpha)(W-C-\alpha)\left(2 P(P+\alpha)+A^{2}(2 P+\alpha)\right)-A P^{2}\left(A^{2}+2(P+\alpha)\right)\right) \xi}{2 P^{2}(P+\alpha)^{3}}$, where A $=P-W+\alpha$. Therefore, if the numerator of the difference, which is $2(P+\alpha)(W-C-\alpha)\left(2 P(P+\alpha)+A^{2}(2 P+\alpha)\right)-A P^{2}\left(A^{2}+2(P+\alpha)\right)$, is nonnegative, we conclude that $\Pi_{M_{O}}^{*} \geq \Pi_{M_{S}}^{*}$. Otherwise, $\Pi_{M_{O}}^{*}<\Pi_{M_{S}}^{*}$. Further, similar to the above approach, from equation (3.18), we simplify manufacturer profit in the unsold-discount case as $\Pi_{M_{B}}^{*}=(W-C) Q_{B}^{*}-B \frac{Q_{B}^{*}}{4 \rho_{B}^{*} \xi}$ and replace $\rho_{B}^{*}$ with $\rho_{B}^{*}=1+\frac{(P-W)^{2}}{2(P-B)}$ and $Q_{B}^{*}$ with $Q_{B}^{*}=\frac{(P-W)\left((P-W)^{2}+2(P-B)\right) \xi}{(P-B)^{2}}$ to derive

$$
\Pi_{M_{B}}^{*}=\frac{(W-C)(P-W)\left((P-W)^{2}+2(P-B)\right) \xi}{(P-B)^{2}}-\frac{B(P-W)^{2}\left((P-W)^{2}+2(P-B)\right) \xi}{2(P-B)^{3}} .
$$

We take the difference in profit in the off-invoice case and the unsolded-discount case as follows:

$$
\begin{aligned}
\Pi_{M_{O}}^{*}- & \Pi_{M_{B}}^{*} \\
= & \frac{(W-C)\left((P-B)^{2}(P-W+\alpha)\left((P-W+\alpha)^{2}+2 P\right) \xi-P^{2}(P-W)\left((P-W)^{2}+2(P-B)\right) \xi\right)}{P^{2}(P-B)^{2}} \\
& -\frac{\alpha(P-W+\alpha)\left(2 P+(P-W+\alpha)^{2}\right) \xi}{P^{2}}+\frac{B(P-W)^{2}\left((P-W)^{2}+2(P-B)\right) \xi}{2(P-B)^{3}} .
\end{aligned}
$$

Given the same trade promotion discount, that is, $\alpha=B$, the function becomes $\frac{\left(2(P-B)^{3}(W-B-C) x+P^{2}(B(P+W-2 C)-2 P(W-C)) y\right) \xi}{2(P-B)^{3} P^{2}}$, where $\mathrm{x}=(P-W+B)\left((P-W+B)^{2}+2 P\right)$ and $y=(P-W)\left((P-W)^{2}+2(P-B)\right)$. Therefore, if the numerator, which is $2(P-B)^{3}(W-B-C) x+$ $P^{2}(B(P+W-2 C)-2 P(W-C)) y$, is non-negative, we conclude that $\Pi_{M_{O}}^{*} \geq \Pi_{M_{B}}^{*}$. Otherwise, $\Pi_{M_{O}}^{*}<\Pi_{M_{B}}^{*}$. 
Finally, in the same way, we compare manufacturer profit in the scan-back case and unsold-discount case. Given the same promotion discount $(\beta=B)$, the difference between profit in both the cases is

$$
\begin{aligned}
& \frac{(W-C)\left((P-B)^{2}(x+2 B(P-W+B))-(P+B)^{2} y\right) \xi}{(P+B)^{2}(P-B)^{2}} \\
& -\frac{B}{2}\left(\frac{(P-B)^{3}(P+W+B)(x+2 B(P-W+B))-(P+B)^{3}(P-W) y}{(P+B)^{3}(P-B)^{3}}\right) \xi,
\end{aligned}
$$

where $x=(P-W+B)\left((P-W+B)^{2}+2 P\right)$ and $y=(P-W)\left((P-W)^{2}+2(P-B)\right)$; further, we use the same intermediate variables as above. It is difficult to judge whether this difference is greater than zero. Therefore, we conduct a numerical study to discuss the topic in more detail.

\section{ENDOGENOUS TRADE PROMOTION}

\subsection{Notations and assumptions}

We use the same assumptions as stated in Section 3 to demonstrate our model and extend some notations mentioned in Section 3. In Section 3, the notation * refers to the optimal value if the channel party maximizes their own profit with given $\operatorname{cost} C$, wholesale price $W$, and retail price $P$ under exogenous trade promotion. In this section, ${ }^{* *}$ refers to the optimal value if the channel party maximizes the channel profit with endogenous trade promotion.

\subsection{Mathematical model}

Endogenous trade promotions are considered to be an important factor determining the manufacturer's profit. Our objective is to determine the maximum profit generated by the optimal order quantity, promotional effort level and trade promotion discount. Thus, it is necessary to separately find the manufacturer's optimal discounts for the three trade promotion cases.

\subsubsection{Off-invoice discount}

Replacing $Q_{O}^{*}$ in $\Pi_{M_{O}}$ with the expression in (3.5), we get equation (3.19) $\Pi_{M_{O}}^{*}$. To get the optimal off-invoice discount, we take the derivative of the manufacturer's profit with respect to trade promotion budget for the off-invoice case:

$$
\begin{aligned}
& \frac{\partial \Pi_{M_{O}}^{*}}{\partial \alpha} \\
& \quad=\frac{\left(3(P-W+\alpha)^{2}(W-\alpha-C)+2 P(W-\alpha-C)-(P-W+\alpha)^{3}-2 P(P-W+\alpha)\right) \xi}{P^{2}} .
\end{aligned}
$$

The optimal trade promotion budget, $\alpha^{*}$, can be derived from the first-order condition $\frac{\partial \Pi_{M_{O}}^{*}}{\partial \alpha}=0$, and we get $\alpha^{*}=\frac{Y_{O}}{12 X_{O}}-(P-W)$, where $X_{O}=3^{1 / 3}\left(9(P-C)\left((P-C)^{2}+8 P\right)+\right.$ $\left.4 \sqrt{6} \sqrt{P\left(27(P-C)^{4}+2 P\left(-9(P-C)^{2}+64 P\right)\right)}\right)^{1 / 3}$ and $Y_{O}=9(P-C)^{2}-48 P+3(P-C) X_{O}+X_{O}^{2}$. Because trade promotion budget cannot be negative, we summarize it as follows:

$$
\alpha^{*}=\left\{\begin{array}{ll}
\frac{Y_{O}}{12 X_{O}}-(P-W), & \frac{Y_{O}}{12 X_{O}}>P-W \\
0, & \text { Otherwise }
\end{array} .\right.
$$




\subsubsection{Scan-back discount}

Next, in the scan-back case, we maximize manufacturer profits with respect to trade promotion discount by solving $\frac{\partial \Pi_{M_{S}}^{*}}{\partial \beta}=0$. We find that

$$
\begin{aligned}
\frac{\partial \Pi_{M_{S}}^{*}}{\partial \beta} & \\
= & \frac{(P-W+\beta)(2+2(P-W+\beta))(2(P+\beta)(W-C-\beta)+\beta(P-W+\beta)) \xi}{2(P+\beta)^{3}} \\
& +\frac{(P-W+\beta)(-2 C-P+W-2 \beta)\left(2(P+\beta)+(P-W+\beta)^{2}\right) \xi}{2(P+\beta)^{3}} \\
& +\frac{(2(P+\beta)(W-C-\beta)+\beta(P-W+\beta))\left(2(P+\beta)+(P-W+\beta)^{2}\right) \xi}{2(P+\beta)^{3}} \\
& \quad-\frac{3(P-W+\beta)(2(P+\beta)(W-C-\beta)+\beta(P-W+\beta))\left(2(P+\beta)+(P-W+\beta)^{2}\right) \xi}{2(P+\beta)^{4}} .
\end{aligned}
$$

Because it is complex to derive the optimal trade promotion budget using first-order condition $\frac{\partial \Pi_{M_{S}}^{*}}{\partial \beta}=0$, we numerically solve for the optimal trade promotion discount. Thus, we summarize optimal trade promotion in the case of scan-back policy as follows:

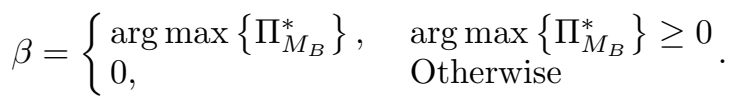

\subsubsection{Unsold-discount budget}

Similar to the above calculation, substituting (3.16) and (3.17) in (3.18), we get equation (3.21) $\Pi_{M_{B}}^{*}$. We find the optimal unsold-discount budget by solving the following first-order condition:

$$
\begin{aligned}
\frac{\partial \Pi_{M_{B}}^{*}}{\partial B}= & \frac{2(P-W)(W-C)\left((P-W)^{2}+(P-B)\right) \xi}{(P-B)^{3}} \\
& -\frac{(P-W)^{2}\left(2(P-B)(2 B+(P-B))+(P-W)^{2}(3 B+(P-B))\right) \xi}{2(P-B)^{4}}=0 . \\
\Rightarrow & B^{*}=\frac{X_{B}-Y_{B}}{2(P+W-2 C)}
\end{aligned}
$$

where $Y_{B}=\sqrt{2 P(P+W-2 C)\left((P-5 W+4 C)\left(P+(P-W)^{2}\right)+P(P-W)\right)+X_{B}^{2}}$ and $X_{B}=4 P(W-C)$ $+(P-W)^{2}(P+W-2 C)$. Only when the numerator of the equation for $B^{*}$, that is, $X_{B}-Y_{B}$, is positive, the discount budget in the unsold-discount case is valid value; otherwise, the discount budget is zero. Thus, we summarize the optimal trade promotion in the unsold-discount case as follows:

$$
B^{*}= \begin{cases}\frac{X_{B}-Y_{B}}{2(P+W-2 C)}, & (P-5 W+4 C)\left(P+(P-W)^{2}\right)+P(P-W)<0 \\ 0, & \text { Otherwise. }\end{cases}
$$

Because we lose analytical tractability with these complicated partial derivatives $\left(\frac{\partial \Pi_{M_{S}}^{*}}{\partial \beta}\right)$, we numerically solve for the optimal scan-back value. Then, we summarize the analytical results in Table 6 . From Table 6 , it is obvious that the optimal decision variables in the off-invoice case are not a function of the wholesale price. In the next section, we discuss the topic in more detail and present the research results. 


\section{NUMERICAL STUDIES}

\subsection{Exogenous trade promotion}

In this section, we consider different numerical settings to better understand the characteristics of the retailer's decision variables - promotional effort and order quantity; further, we analyze the effect of trade policies on manufacturers' and retailers' profits when the amount of discount under the three different trade promotion policies is the same. Given that product cost to the manufacturer $C=20$, wholesale price $W=80$, and retail price $P=150$, Table 3 summarizes the theoretical predictions for the retailer's promotional effort levels, order quantities, and retailer and manufacturer profits at specific amounts of trade promotion discounts under off-invoice (OI), scan-back (SB), and unsold-discount (UB) policies. For simplicity, hereafter, we assume that demand factor $\xi$ equals 1.

From Table 3, the comparison between promotional efforts under different trade promotion policies shows that promotional efforts are the maximum in the case of off-invoice policy compared to the other two policies given the same amount of trade promotion discount. Further, the difference in the promotional efforts is significant, which supports Proposition 3.1. In Table 3, also consistent with our prediction, we find that given the same trade promotion discount, the retailer's order quantity and profit are the maximum when trade promotions are allocated to off-invoice policy than other policies. These results support Propositions 3.2 and 3.3. The results show that the retailers prefer to get the off-invoice policy than scan-back and un-sold discount. They could ask for off-invoice contracts when discussing with the manufacturers.

From the promotional effort level column, we observe that as trade promotions discounts increase, the promotional effort level also increases. However, in most of the existing literature, the employs trade promotion with an aim to induce retailers to pass on some discount to the consumers and subsequently increase retail sales (e.g., $[12,14])$. In our research, we assume that the retailer passes on the trade promotion discount through sales promotion to stimulate sales. This assumption is also consistent with our numerical result. In Figures 1a and 1c, applying the two-level promotion could increase the promotional effort and also increase the retailer and channel's profit. Moreover, in Figure 1c, we observe that the channel's profit is the highest when the manufacturer provides an off-invoice discount to the retailer among the three policies. However, in the manufacturer's case, the manufacturer's profits have different results under the three trade promotion policies for different amounts of trade promotion discount (Fig. 1b).

In sum, the use of two-level promotion always benefits to the retailer and channel. However, while the unsolddiscount policy guarantees the manufacturer's profit, the retailer prefers to get the off-invoice and scan-back policy than the unsold-discount policy. The manufacturer needs to set a reasonable discount to increase its profit and satisfy the retailer.

\subsection{Endogenous trade promotion}

In this section, we study the effect of optimal trade promotion on the channels' profits using numerical examples. To cover a broad range of potential characteristics, we perform numerous computational tests. Firstly, to examine the effects of the manufacturer's unit cost, example 1-1 was solved varying $C$ from 0 to 32 with the following base parameter set: $W=40, P=60$, and $\xi=1$, the results of which are presented in Table 4 . Moreover, we altered the demand factor $\xi=1$ to $\xi=1.2$, and the results (example 1-2) are presented in Table 5 . In addition, we examined the effects of the wholesale price (example 2) and retail price (example 3 ), and the results are separately presented in Tables 7 and 8 .

To simplify Tables 4, 5, and 7, we present the findings in Figures 2, 3, and 4 . The following observations can be made from the abovementioned tables:

(1) From Tables 4 and 5, it can be seen that the demand factor only influences the retailer's ordering policy and profit and the manufacturer's profit. Further, we obtain the same results by observing the basic model in Section 3. 


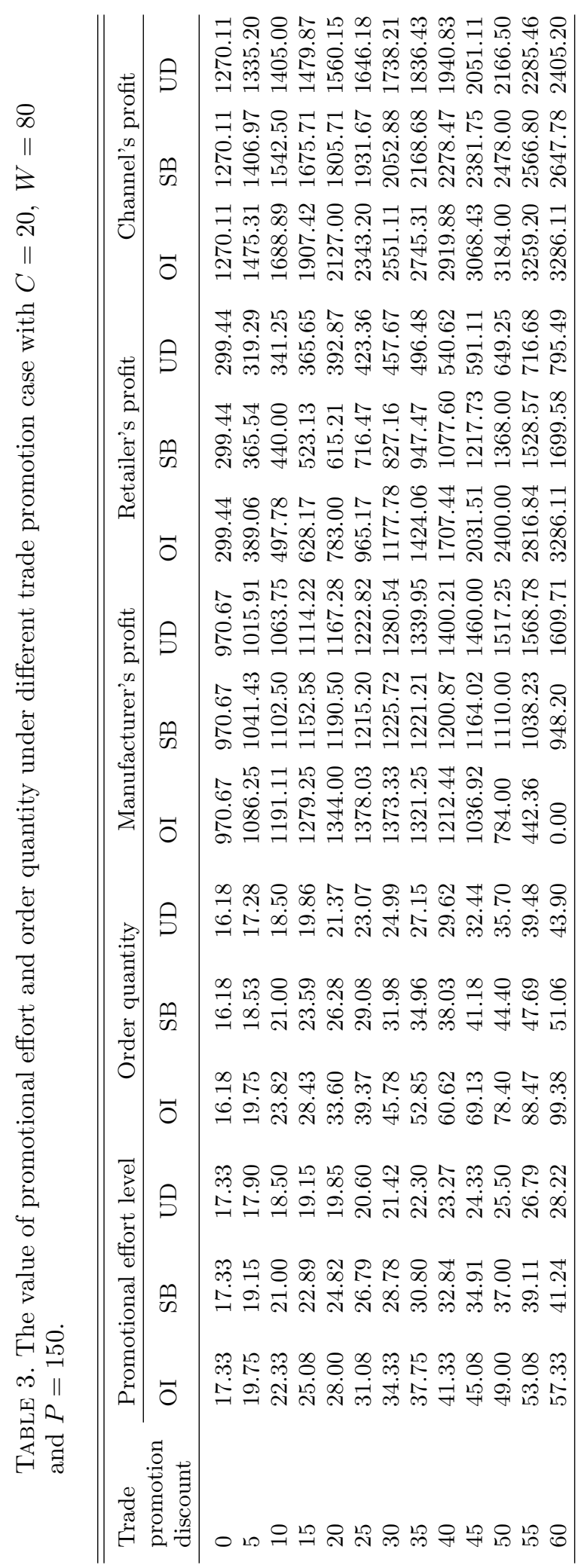




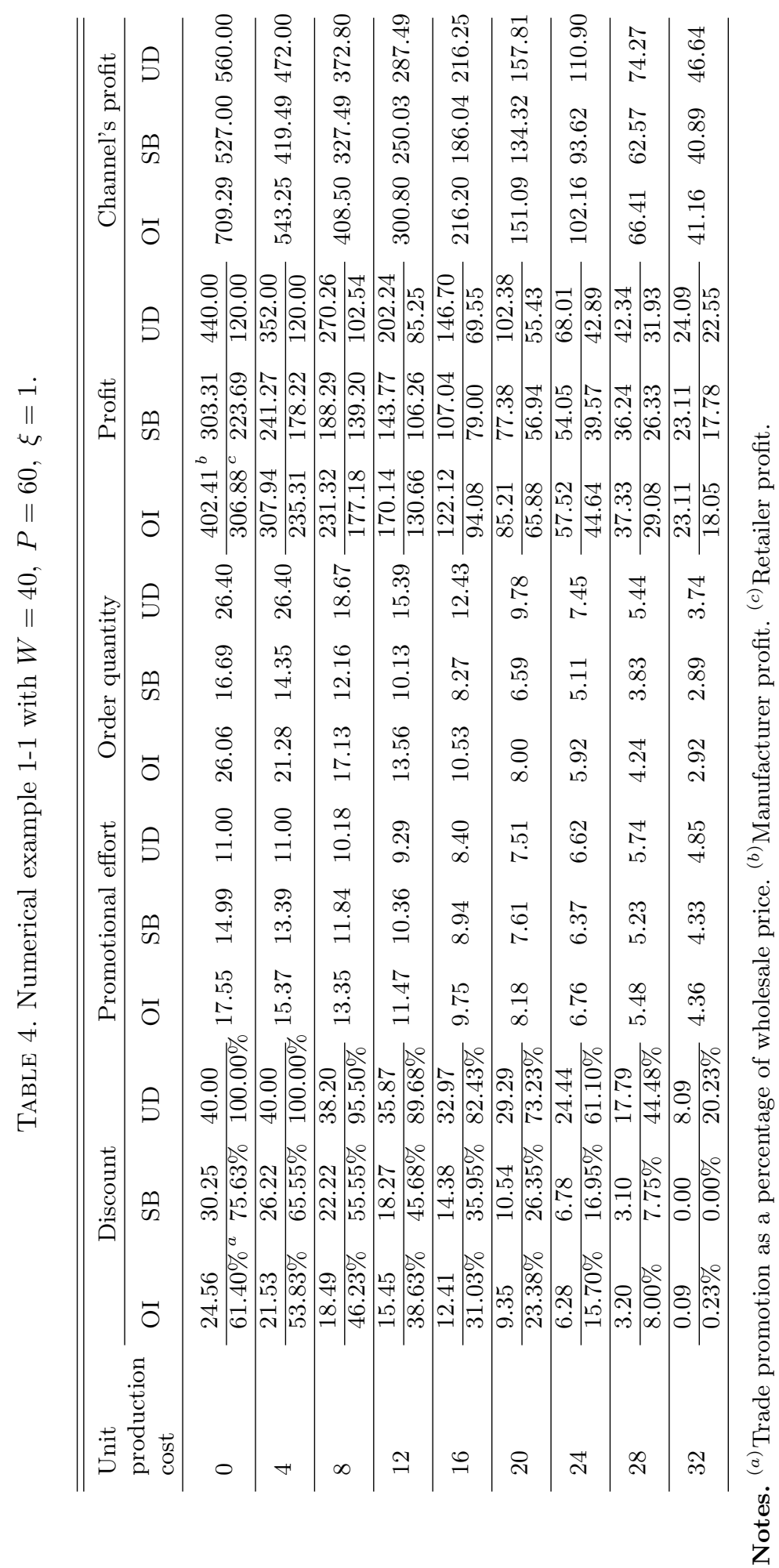




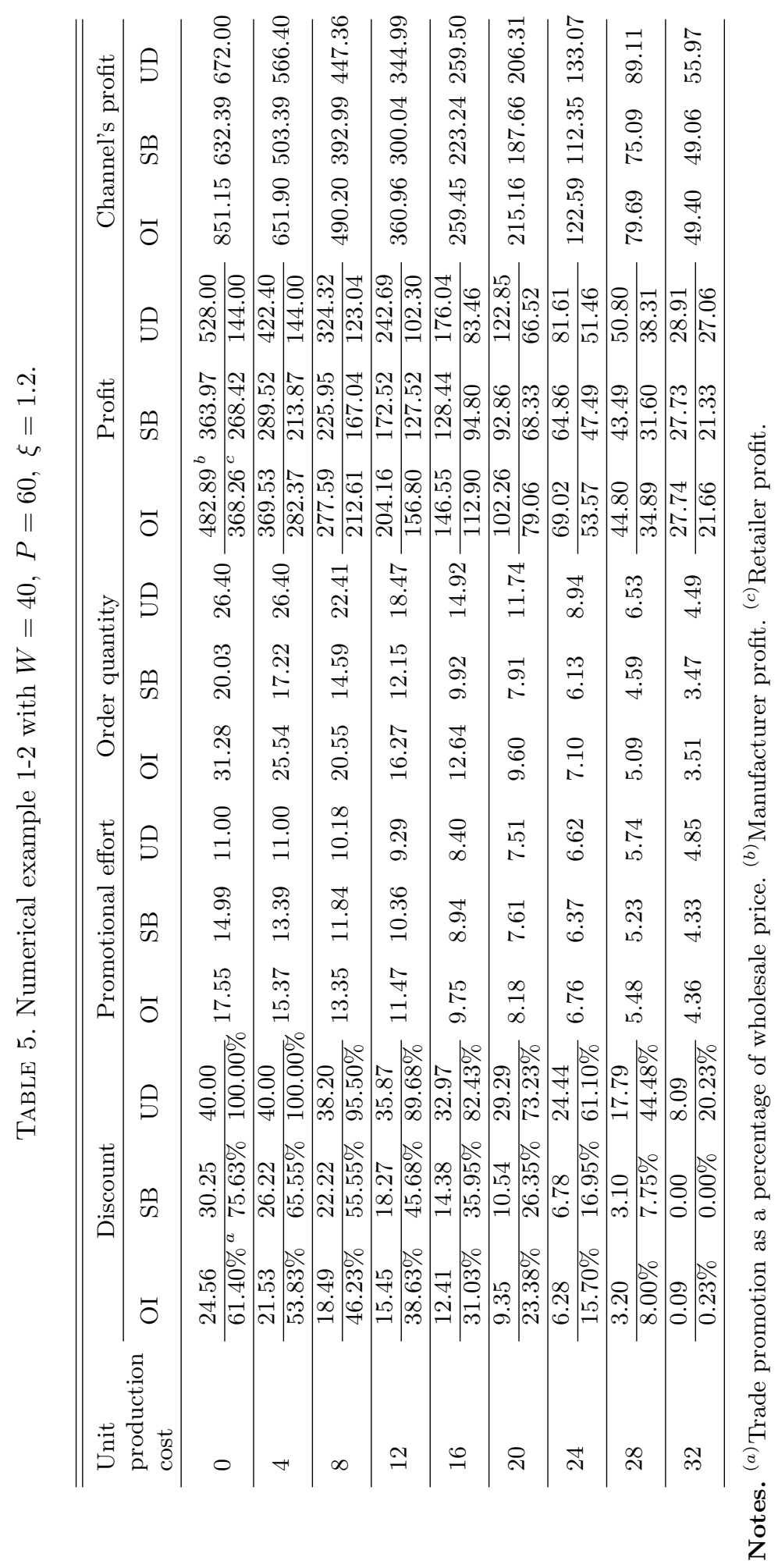




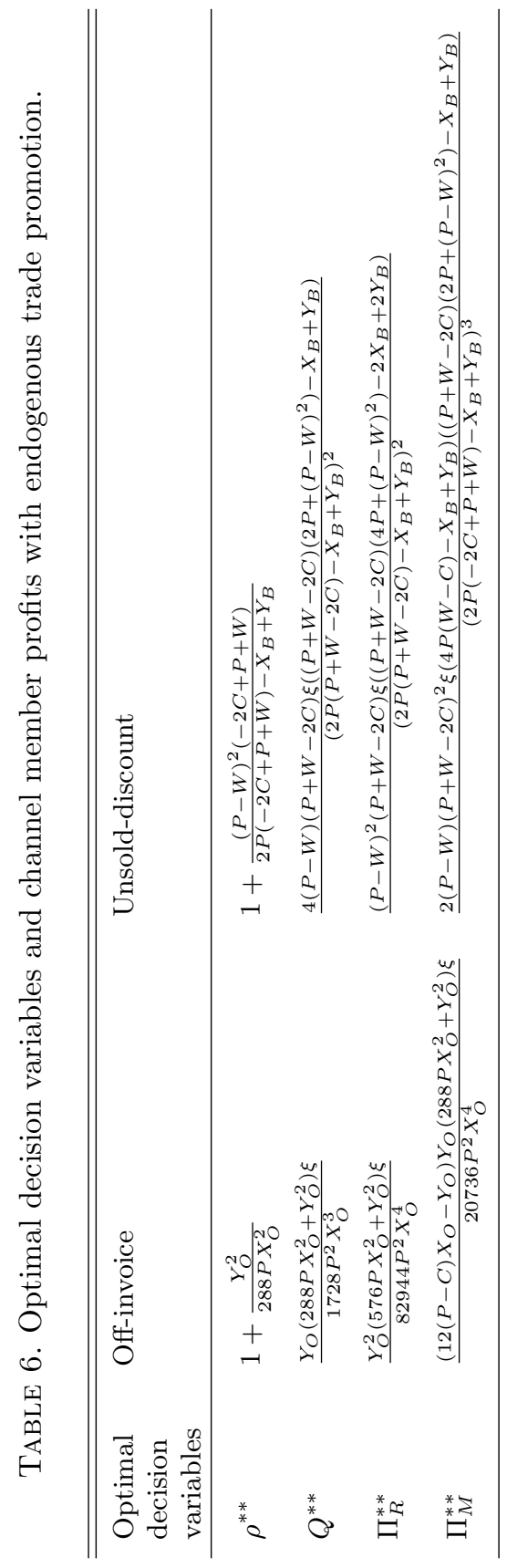


Y.-C. TSAO ET AL.

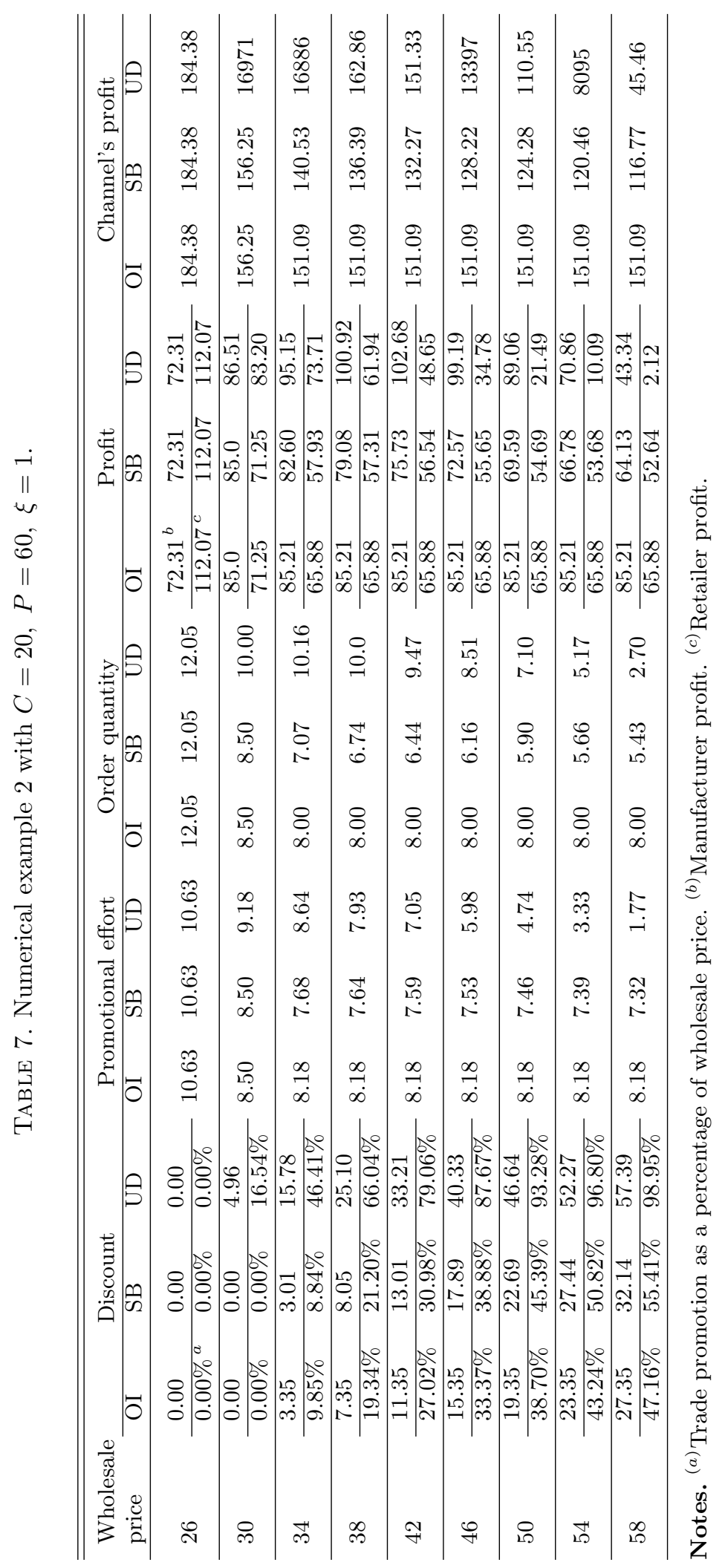




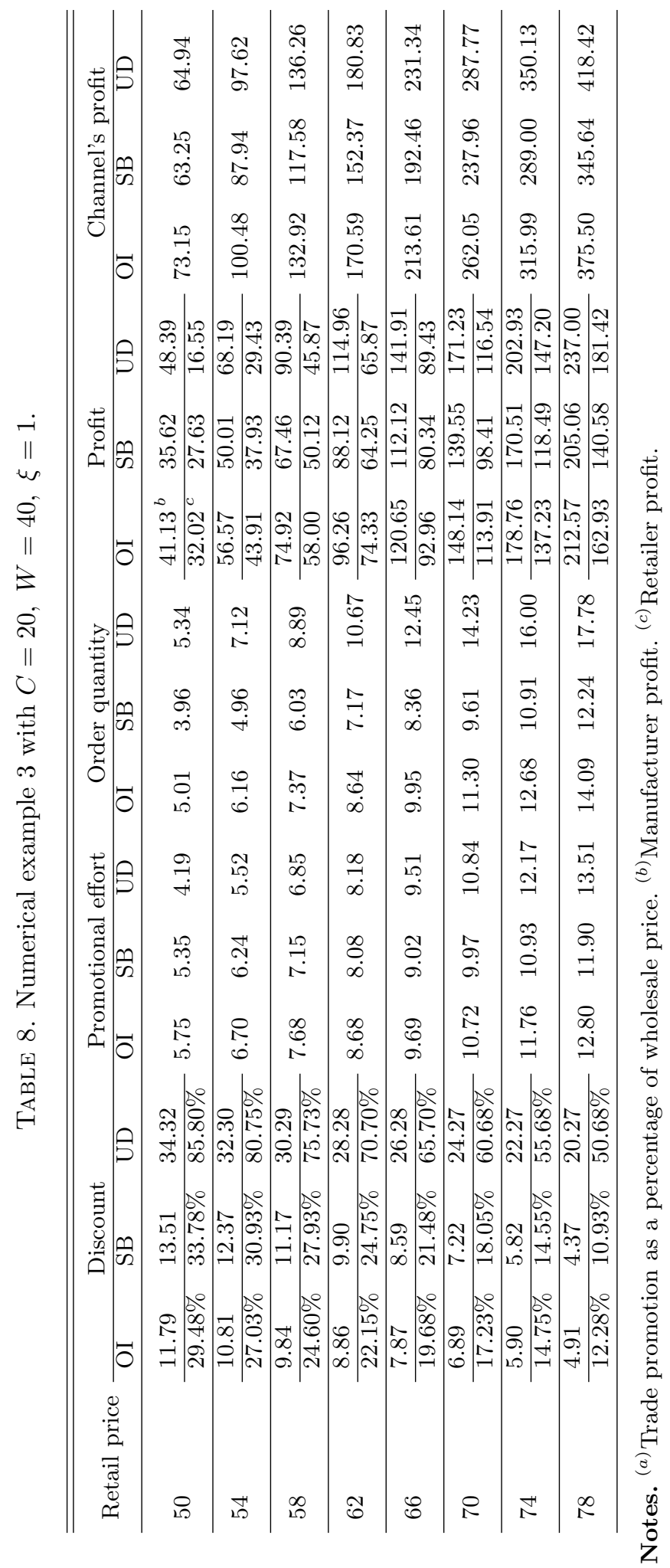




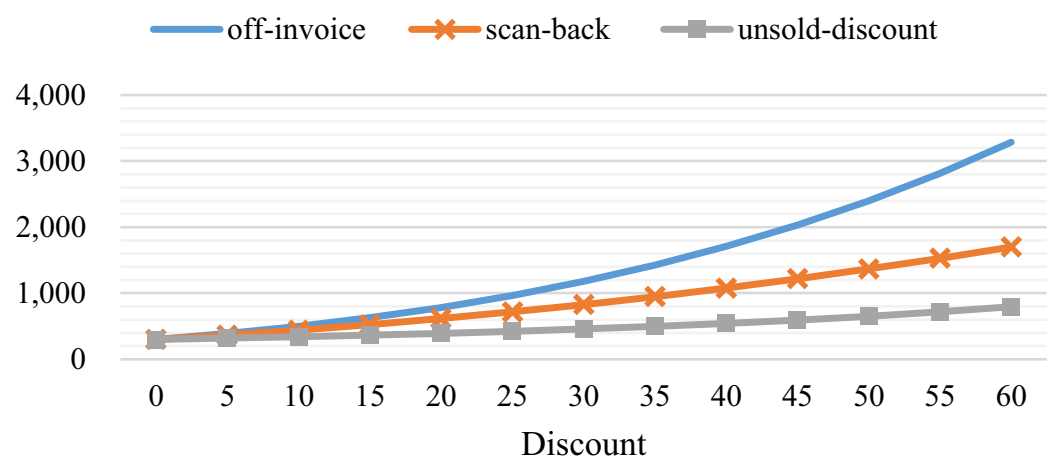

(a)

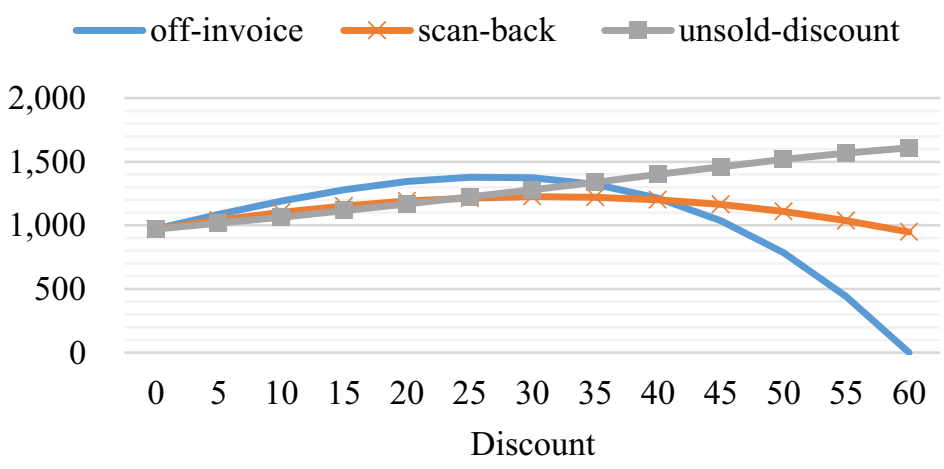

(b)
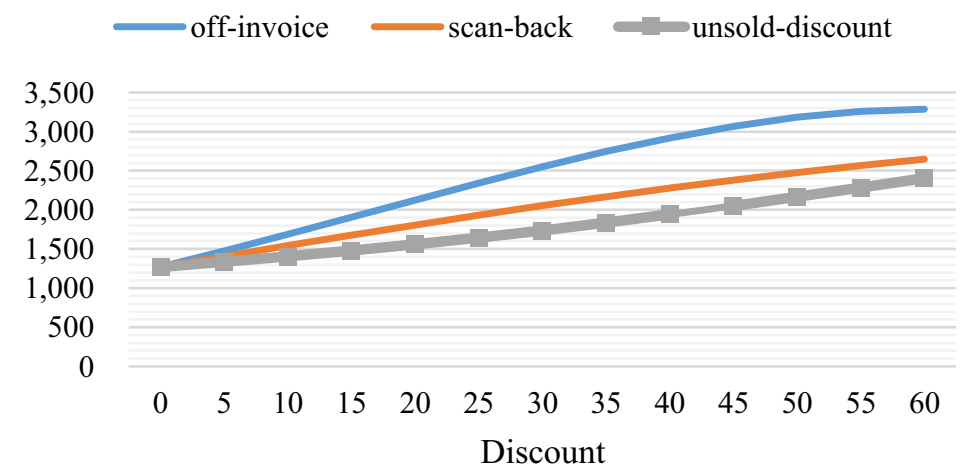

(c)

FiguRE 1. Influences of different exogenous trade promotion discount. (a) Retailer's profit, (b) Manufacturer's profit and (c) Channel's profit.

(2) For the manufacturer, the trade promotion discount tends to increase as either $W$ increases or $C$ decreases. In other words, the manufacturer tends to give more trade promotion discount when he/she has a relatively high marginal income $(W-C)$ or the retailer has a relatively low marginal income $(P-W)$.

(3) Through Figure 2 to Table 5, we find that the retailer's promotional effort level, order quantity, and channel members' profits are higher when trade promotions are allocated to the off-invoice policy versus the scan- 


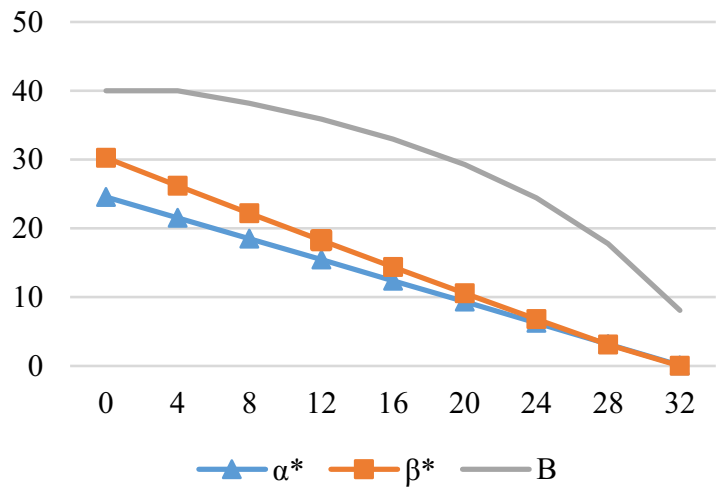

(a)

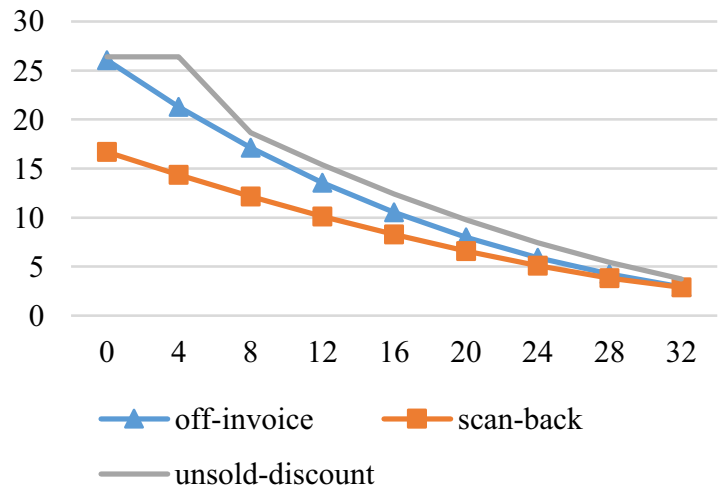

(c)

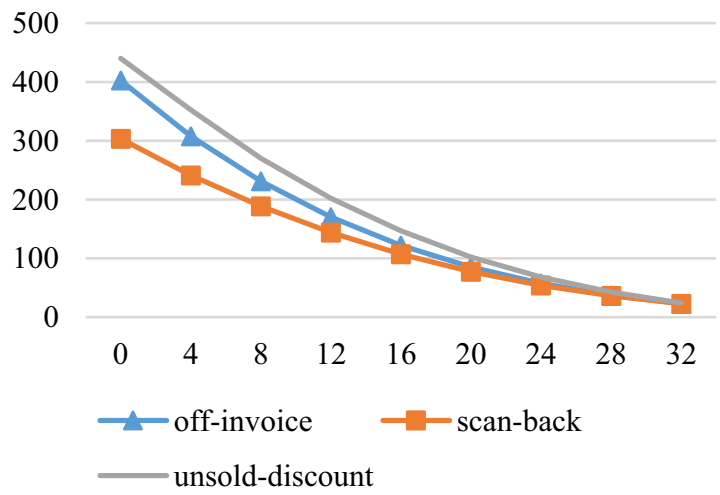

(e)

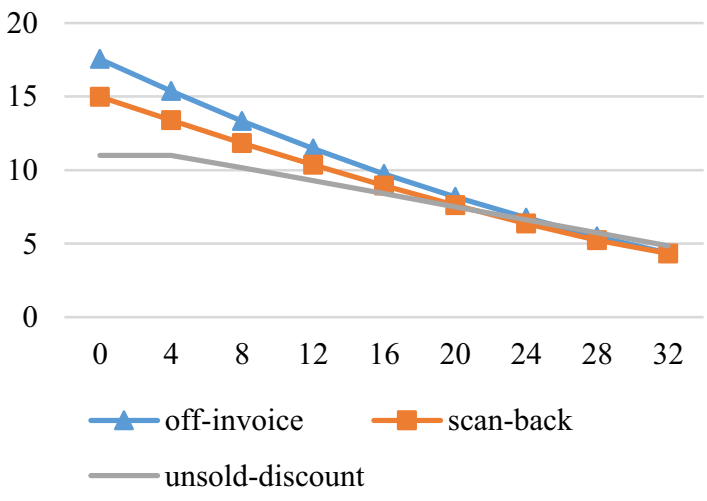

(b)

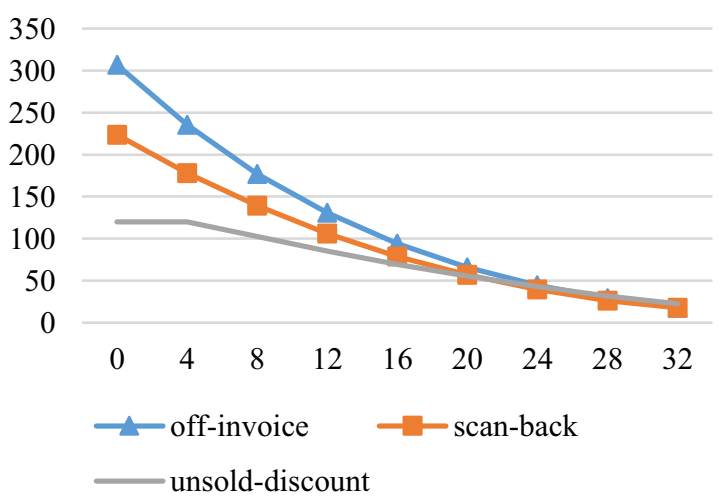

(d)

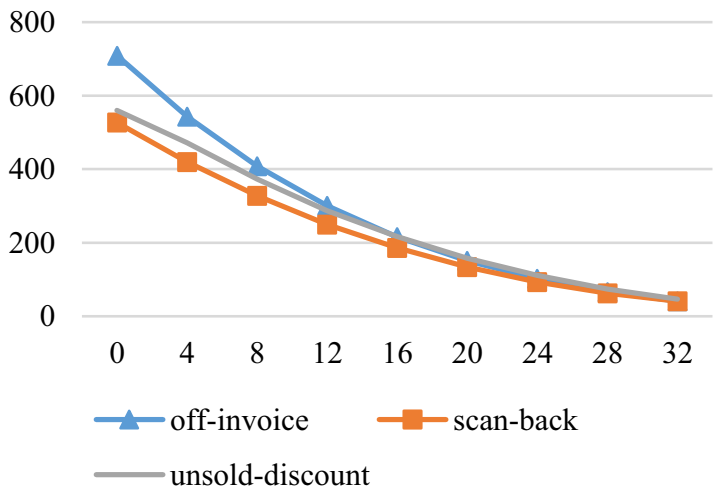

(f)

Figure 2. Influences of different cost (example 1) with $W=40, P=60, \xi=1$. (a) Trade promotion discount, (b) Promotional effort, (c) Order quantity, (d) Retailer profit, (e) Manufacturer profit and (f) Channel's profit. 


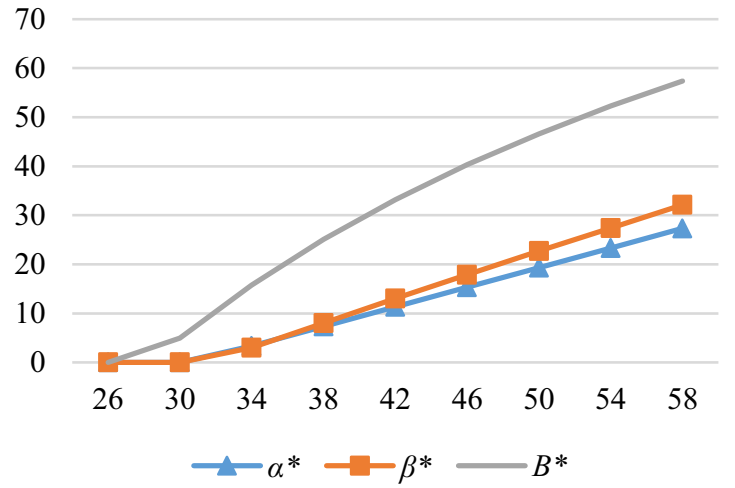

(a)

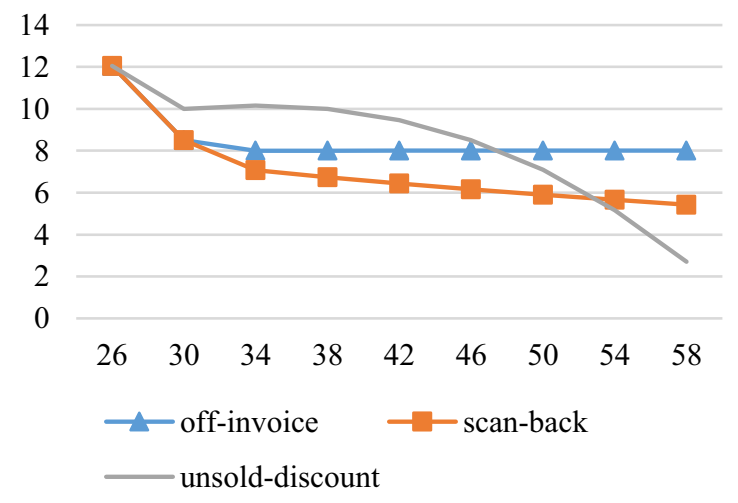

(c)

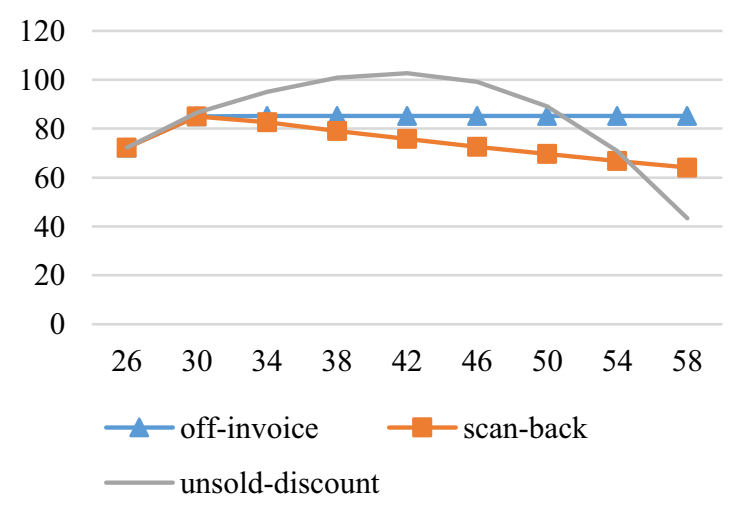

(e)

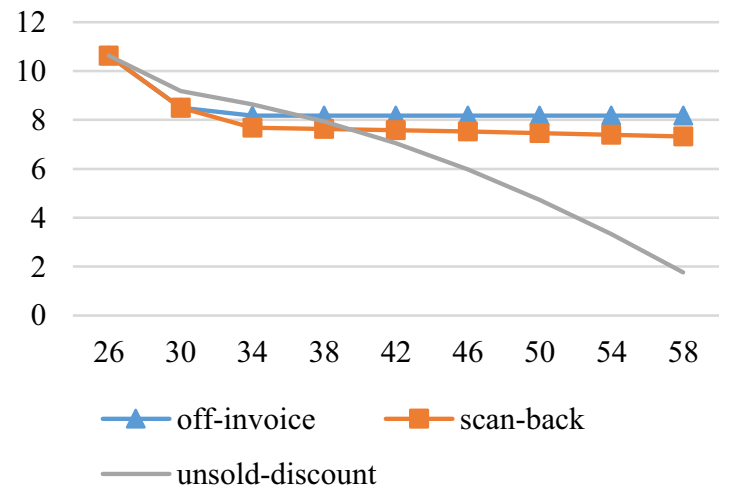

(b)

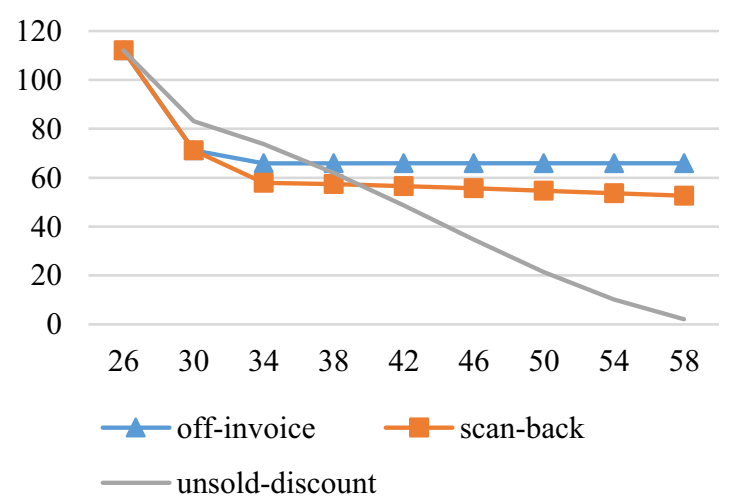

(d)

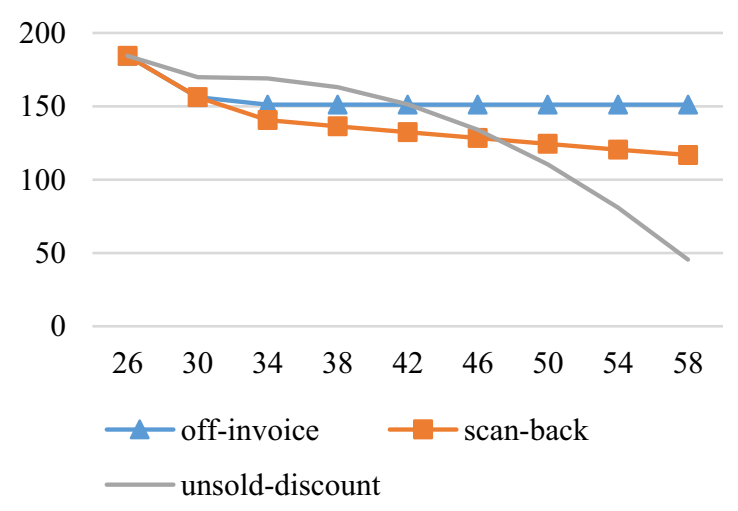

(f)

Figure 3. Influences of different wholesales price (example 2) with $C=20, P=60, \xi=1$.

(a) Trade promotion discount, (b) Promotional effort, (c) Order quantity, (d) Retailer profit,

(e) Manufacturer profit and (f) Channel's profit. 


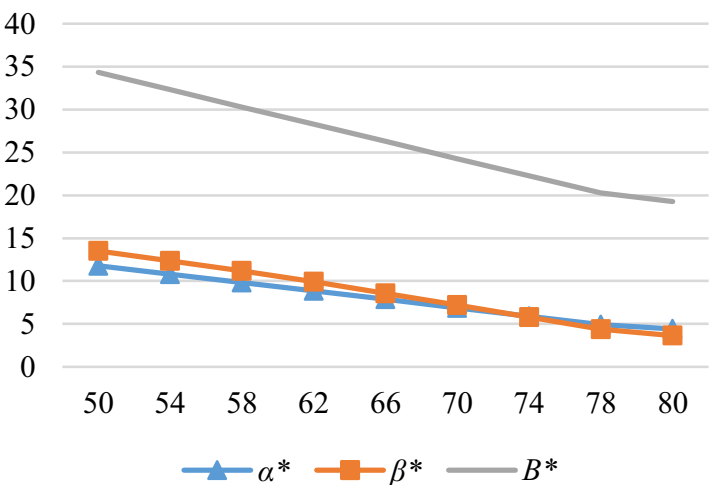

(a)

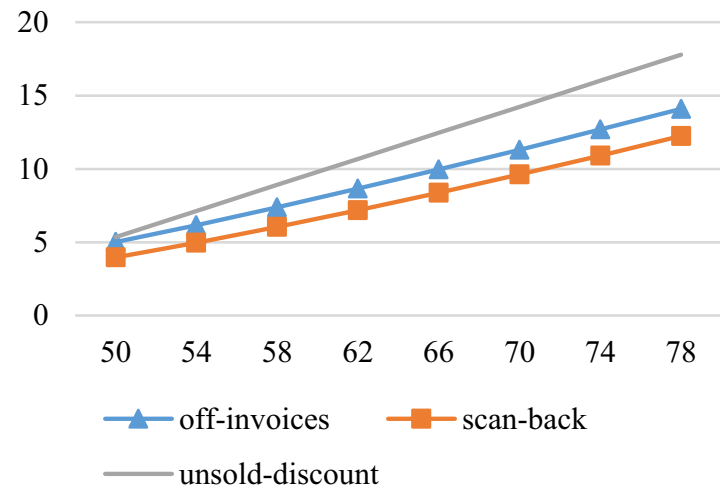

(c)

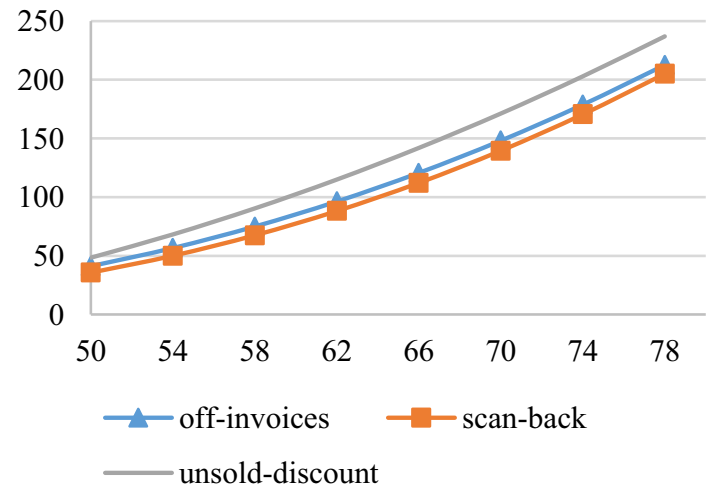

(e)



(b)

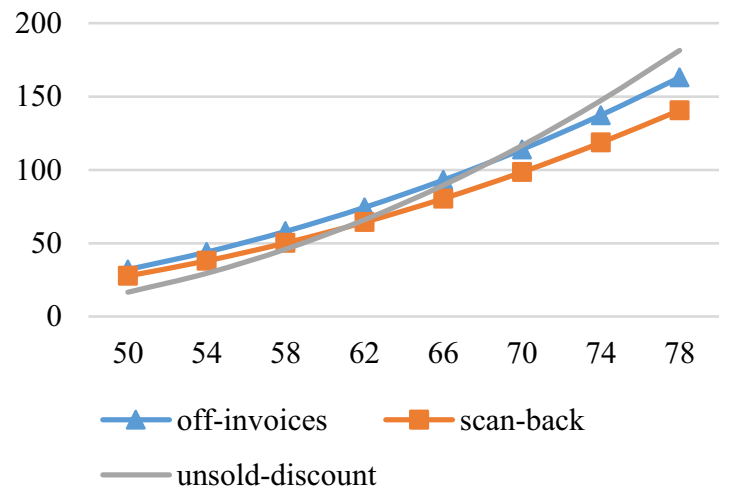

(d)

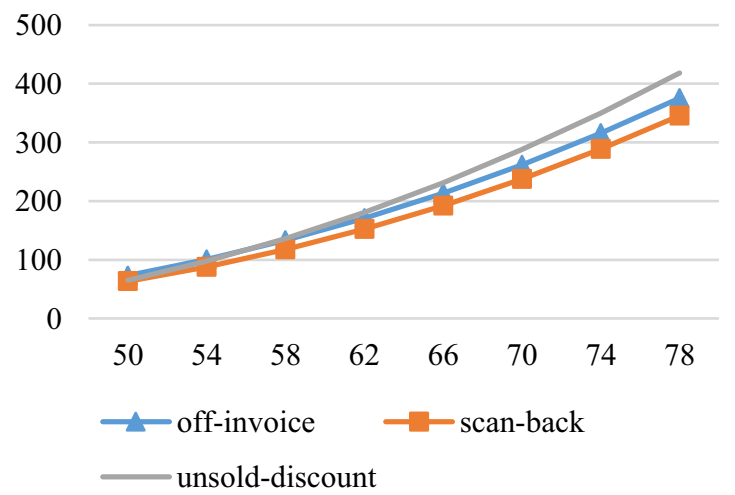

(f)

Figure 4. Influences of different retail price (example 3) with $C=20, W=40, \xi=1$. (a) Trade promotion discount, (b) Promotional effort, (c) Order quantity, (d) Retailer profit,

(e) Manufacturer profit and (f) Channel's profit. 
back policy. However, the unsold-discount policy is the best policy for the manufacturer. Both of them could discuss to get a suitable policy for each case. For example, if they apply the off-invoice for trade promotion, they need to discuss a balance discount amount to satisfy the manufacturers. For both retailer and channel, they could get a higher profit in case of using the off-invoice policy at whatever discount level.

(4) From Figure 3, we find that when the wholesale price increases in the off-invoice case for a given cost and retail price, the retailer's decision variables and profit and the manufacturer's profit will not be influenced by the wholesale price. This can also be observed from Table 6 . It is consistent with the above observations; the manufacturer's profit is not stable in case of using the off-invoice policy. He/She could also keep his/her profit's balance by adjusting the wholesale price.

(5) From Figures 2e, 3e, and 4e, we find that the wholesale price is a key factor influencing the manufacturer's profit under the three different trade promotion policies. As the above discussion, the manufacturer tends to give more trade promotion discount when he/she has a relatively high marginal income $(W-C)$. An increase in the wholesale price increases the high marginal income. However, it is not easy for the manufacturer to increase the wholesale price, it still has other factors need to care: competition, willing of customer, ... In the future, we could consider other factors to the wholesale price and determine the best price for the manufacturer.

When trade promotion is provided by the manufacturer, there exists an optimal level of discount that maximizes the manufacturer's profit under demand uncertainty. From Tables 4, 5, 7, and 8, we find that this optimal trade promotion discount is the largest under unsold-discount policy.

\section{Conclusions}

In this research, we develop models considering a distribution system comprising a single manufacturer who sells a product to a retailer, who in turn sells it to end consumers The manufacturer undertakes trade promotion to increase the retailer's order quantity and the retailer undertakes sales promotion to stimulate consumer demand We assume that end consumer demand is simultaneously dependent on promotional effort and is random Three trade promotion policies are investigated separately: off-invoice policy, scan-back policy, and unsold-discount policy. Two different models are considered: (1) exogenous trade promotion decision and (2) endogenous trade promotion decision. The objective of the first model is to determine the optimal order quantity and the level of promotional effort to maximize the retailer's profit. We find that, under exogenous trade promotion, the retailer's promotional effort level, order quantity, and channel's profit are highest in the off-invoice policy. Using the off-invoice trade promotion, the retailer can obtain the maximum product discount from the manufacturer to increase consumer demand by undertaking sales promotion. Furthermore, when the exogenous trade promotion discount increases, the retailer prefers to undertake more promotional effort. With varying exogenous trade promotion discounts, the manufacturer's profits under the three trade promotion policies are different. However, from the channel's point of view, we find that when the manufacturer offers off-invoice trade promotion discount to the retailer, the channel's profit is highest when compared to the other two promotion policies.

The second model extends the first to consider endogenous trade promotion and determine the optimal trade promotion discount to maximize the manufacturer's profit. From numerical examples, we find that the retailer's promotional effort level, order quantity, and profit, and the manufacturer's profit are higher when trade promotions are allocated to off-invoice policy versus scan-back policy. In addition, we conclude that the wholesale price is a key factor influencing manufacturer profits when we compare the three different trade promotion policies. Moreover, we demonstrate that the retailer's order quantity, promotional effort, and profit, and the manufacturer's profit are not influenced by the wholesale price when the manufacturer offers an offinvoice trade promotion discount. Finally, regarding the optimal trade promotion discount, the manufacturer provides the largest amount of discount in the case of unsold-discount policy.

The study only considers the two-level promotion in the general supply chain. However, in practice, the development of concepts: credit financing, trade credit; advance-cash-credit payment; carbon emission make the 
supply chain become more complicated. Therefore, how to combine benefits from trade/sale promotion with other financing policies to improve the supply chain performance is a critical problem in the future works. In addition, the demand is assumed to be a promotional effort dependent function in these models. However, with many types of goods, i.e. the deteriorating item, time is one of key factor in the inventory model. The demand function could include time factor in the future research. This paper considers one retailer and one manufacturer in our system, in reality, an extension of our study is to consider horizontal competition (between retailers). Furthermore, it would be interesting to incorporate some parameters in our research such as pass-through rates (i.e., how much trade promotion discount is passed on from the manufacturer to the consumer) because the manufacturer cannot monitor the retailer's actual promotion efforts in the off-invoice case.

\section{Appendix A. Proofs for Propositions 3.1-3.3}

Proof of Proposition 3.1. The promotional effort $\rho_{o}^{*}>\rho_{s}^{*}>\rho_{B}^{*}$. We compare the sales promotion effort levels by calculating difference between the levels under the two abovementioned policies, given equal trade promotion discounts $(\alpha=\beta=B)$. We find that $\rho_{o}^{*}-\rho_{s}^{*}=\frac{\alpha(P-W+\alpha)^{2}}{2 P(P+\alpha)}$ and $\rho_{s}^{*}-\rho_{B}^{*}=\frac{\beta(W(P-W)+(W-\beta)(P+\beta-W))}{2\left(P^{2}-\beta^{2}\right)}$. Because $\rho_{o}^{*}-\rho_{s}^{*}>0$ and $\rho_{s}^{*}-\rho_{B}^{*}>0$, we conclude that $\rho_{o}^{*}>\rho_{s}^{*}>\rho_{B}^{*}$.

Proof of Proposition 3.2. The order quantities, $Q_{O}^{*}>Q_{S}^{*}>Q_{B}^{*}$. The order quantities are decision variables for the retailer. The order quantity in the off-invoice case is $\frac{2 \xi(P-W+\alpha)}{P} \rho_{O}^{*}$, and the order quantity in the scan-back case is $\frac{2 \xi(P+\beta-W)}{(P+\beta)} \rho_{S}^{*}$. Because we conclude that $\rho_{o}^{*}>\rho_{s}^{*}>\rho_{B}^{*}$, it is obvious that given the same discount budget $(\alpha=\beta)$, the first term in the off-invoice case is greater than that in the scan-back case. Therefore, we can conclude that $Q_{O}^{*}>Q_{S}^{*}$. Further, the order quantity in the unsold-discounted case is $\frac{2 \xi(P-W)}{(P-B)} \rho_{B}^{*}$. The first term is smaller than that in the off-invoice case. We find that $Q_{O}^{*}>Q_{B}^{*}$.

Because we cannot compare the order quantities in the cases of scan-back and unsold-discount policies by using the aforementioned approach, we compare them by calculating the difference in the order quantities. We find that

$$
\begin{aligned}
Q_{S}^{*}-Q_{B}^{*}= & \frac{\xi}{(P-B)^{2}(P+\beta)^{2}}\left((P-B)^{2}(P-W+\beta)\left((P-W+\beta)^{2}+2(P+\beta)\right)\right. \\
& \left.-(P+\beta)^{2}(P-W)\left((P-W)^{2}+2(P-B)\right)\right) .
\end{aligned}
$$

Given the same trade promotion discount, the numerator becomes $(P-W+B)(P-B)^{2}\left((P-W+B)^{2}+\right.$ $2(P+B))-(P+B)^{2}(P-W)\left((P-W)^{2}+2(P-B)\right)$. We know that order quantities are the same when the discount budgets are zero. Thus, if the numerator, which is $(P-W+B)(P-B)^{2}$ $\left((P-W+B)^{2}+2(P+B)\right)-(P+B)^{2}(P-W)\left((P-W)^{2}+2(P-B)\right)$, is positive, we can conclude that $Q_{S}^{*}>Q_{B}^{*}$. Otherwise, $Q_{S}^{*}<Q_{B}^{*}$. On the other hand, because we have $Q_{S}^{*}=\frac{2 \xi(P+\beta-W)}{(P+\beta)} \rho_{s}^{*}, Q_{B}^{*}=\frac{2 \xi(P-W)}{(P-B)} \rho_{B}^{*}$, and $\rho_{s}^{*}>\rho_{B}^{*}$, which we proved in the previous section, we compare $\frac{(P+\beta-W)}{(P+\beta)}$ and $\frac{(P-W)}{(P-B)}$ by taking the difference between them. Given the same amount of discount, we find that $\frac{(P+B-W)}{(P+B)}-\frac{(P-W)}{(P-B)}=-\frac{B(P-2 W+B)}{(P-B)(P+B)}$. Hence, if $P-2 W+B<0$, we can also conclude that $Q_{S}^{*}>Q_{B}^{*}$. This approach is not as rigorous as the former approach because we cannot be sure if $P-2 W+B>0$, the order quantity in the scan-back case will less than that in the unsold-discounted case.

Proof of Proposition 3.3. The retailer's profit, $\Pi_{R_{O}}^{*}>\Pi_{R_{S}}^{*}>\Pi_{R_{B}}^{*}$. First, we compare the retailer's profit in the off-invoice case and scan-back case by taking the difference between profits in each case. We find that

$$
\Pi_{R_{O}}^{*}-\Pi_{R_{S}}^{*}=\frac{\xi}{4}\left(\frac{(P-W+\alpha)^{2}\left(4 P+(P-W+\alpha)^{2}\right)}{P^{2}}-\frac{(P-W+\beta)^{2}\left(4(P+\beta)+(P-W+\beta)^{2}\right)}{(P+\beta)^{2}}\right) .
$$


Given the same trade promotion discount, that is, $\alpha=\beta$, the function can be written as $\frac{(P-W+\alpha)^{2} \alpha\left(4 P(P+\alpha)+(P-W+\alpha)^{2}(2 P+\alpha)\right) \xi}{4 P^{2}(P+\alpha)^{2}}$. Because $\Pi_{R_{O}}^{*}-\Pi_{R_{S}}^{*}>0$, we conclude that the retailer's profit in the off-invoice case is greater than that in the scan-back case.

Next, we compare the retailer's profit in the off-invoice case and the unsold-discount case by taking the difference in profits in each case. We find that

$$
\Pi_{R_{O}}^{*}-\Pi_{R_{B}}^{*}=\frac{\xi}{4}\left(\frac{(P-W+\alpha)^{2}\left(4 P+(P-W+\alpha)^{2}\right)}{P^{2}}-\frac{(P-W)^{2}\left(4(P-B)+(P-W)^{2}\right)}{(P-B)^{2}}\right) .
$$

Given the same trade promotion discount, that is, $\alpha=B$, the numerator becomes $\frac{(P-W+\alpha)^{2}}{P^{2}}$ $\left(4 P+(P-W+\alpha)^{2}\right)-\frac{(P-W)^{2}}{(P-\alpha)^{2}}\left(4(P-\alpha)+(P-W)^{2}\right)$.

We then separately compare the first part $\left(\right.$ i.e., $\frac{(P-W+\alpha)^{2}}{P^{2}}$ and $\left.\frac{(P-W)^{2}}{(P-\alpha)^{2}}\right)$ and the second part (i.e., $4 P+$ $(P-W+\alpha)^{2}$ and $\left.4(P-\alpha)+(P-W)^{2}\right)$ of each term. The difference between $\frac{(P-W+\alpha)^{2}}{P^{2}}$ and $\frac{(P-W)^{2}}{(P-\alpha)^{2}}$ can be written as $\frac{P-W+\alpha}{P}-\frac{P-W}{P-\alpha}$. We find that $\frac{P-W+\alpha}{P}-\frac{P-W}{P-\alpha}=\frac{\alpha(W-\alpha)}{P(P-\alpha)}>0$. Besides, it is obvious that the second part of first term is greater than that of the second term (i.e., $\left.4 P+(P-W+\alpha)^{2}>4(P-\alpha)+(P-W)^{2}\right)$. Therefore, we conclude that $\Pi_{R_{O}}^{*}>\Pi_{R_{B}}^{*}$ given the same amount of trade promotion discount.

Finally, we compare the retailer's profit in the scan-back case and in the unsold-discount case. The difference can be written as

$$
\begin{aligned}
\Pi_{R_{S}}^{*}-\Pi_{R_{B}}^{*}= & \frac{(P-W+\beta)^{2}}{4(P+\beta)^{2}}\left((P-W+\beta)^{2}+4(P+\beta)\right) \xi \\
& -\frac{(P-W)^{2}}{4(P-B)^{2}}\left((P-W)^{2}+4(P-B)\right) \xi
\end{aligned}
$$

We compare the first term $\left(\frac{(P-W+\beta)^{2}}{4(P+\beta)^{2}}\right.$ and $\left.\frac{(P-W)^{2}}{4(P-B)^{2}}\right)$ and the second term $\left((P-W+\beta)^{2}+4(P+\beta)\right.$ and $\left.(P-W)^{2}-4(P-B)\right)$ separately. Let $g_{s}(\beta)=\frac{(P-W+\beta)^{2}}{4(P+\beta)^{2}}$ and $g_{B}(B)=\frac{(P-W)^{2}}{4(P-B)^{2}}$. On comparing the first term in each case by taking the difference, we obtain the function, $g_{s}(\beta)-g_{B}(\beta)=\frac{(P-W+\beta)^{2}}{(2(P+\beta))^{2}}-\frac{(P-W)^{2}}{(2(P-\beta))^{2}}$. By calculating the square root and taking the difference, we can represent the function as $\frac{P-W+\beta}{2(P+\beta)}-\frac{P-W}{2(P-\beta)}=-\frac{\beta(P-2 W+\beta)}{2(P-\beta)(P+\beta)}$. If $P-2 W+\beta<0$, implies that $g_{s}(\beta)>g_{B}(\beta)$. Further, because $(P-W+\beta)^{2}=(P-W)^{2}+2 \beta(P-W)+\beta^{2}$, it is obvious that the second term in the case of scan-back policy is greater than that in the case of unsolddiscount policy. Thus, we can conclude that $\Pi_{R_{S}}^{*} \geq \Pi_{R_{B}}^{*}$ when $P-2 W+\beta<0$; however, it is uncertain that when $P-2 W+\beta>0$, the retailer's profit in the scan-back case will be less than that in the unsold-discount case.

Acknowledgements. This paper is supported in part by the Ministry of Science and Technology in Taiwan under grant 108-2636-E-011-004 and 109-2636-E-011-006.

\section{REFERENCES}

[1] Q.G. Bai, M.Y. Chen and L. Xu, Revenue and promotional cost-sharing contract versus two-part tariff contract in coordinating sustainable supply chain systems with deteriorating items. Int. J. Prod. Econ. 187 (2017) 85-101.

[2] R.C. Blattberg and S.A. Neslin, Sales Promotion: Concepts, Methods and Strategies. Prentice Hall Paper (1990).

[3] Beacon, Trade promotion best practices: a short guide on how to get started. Tab Analytics (2017).

[4] T.H. Cui, J.S. Raju and Z.J. Zhang, A price discrimination model of trade promotions. Marketing Sci. 27 (2008) $779-795$. 
[5] X. Dreze and D.R. Bell, Creating win-win trade promotions: theory and empirical analysis of scan-back trade deals. Marketing Sci. 22 (2003) 16-39.

[6] X. Fang and F.J. Yuan, The coordination and preference of supply chain contracts based on time-sensitivity promotional mechanism. J. Manage. Sci. Eng. 33 (2018) 158.

[7] M. Gumus, P. Kaminsky and S. Mathur, The impact of product substitution and retail capacity on the timing and depth of price promotions: theory and evidence. Int. J. Prod. Res. 54 (2016) 2108-2135.

[8] K.H. Hahn, H. Hwang annd S.W. Shinn, A returns policy for distribution channel coordination of perishable items. Eur. J. Oper. Res. 152 (2004) 770-780.

[9] S. Jorgensen, S. Taboubi and G. Zaccour, Retail promotions with negative brand image effects: is cooperation possible? Eur. J. Oper. Res. 150 (2003) 395-405.

[10] H.M. Kim, Consumers' responses to price presentation formats in rebate advertisements. J. Retailing 82 (2006) $309-317$.

[11] H. Krishnan, R. Kapuscinski and D.A. Butz, Coordinating contracts for decentralized supply chains with retailer promotional effort. Manage. Sci. 50 (2004) 48-63.

[12] N. Kumar, S. Rajiv and A. Jeuland, Effectiveness of trade promotions: analyzing the determinants of retail pass through. Marketing Sci. 20 (2001) 382-404.

[13] H. Kurata and X.H. Yue, Trade promotion mode choice and information sharing in fashion retail supply chains. Int. J. Prod. Econ. 114 (2008) 507-519.

[14] R. Lal and J.M. Villas-Boas, Price promotions and trade deals with multiproduct retailers. Manage. Sci. 44 (1998) $935-949$.

[15] B. Li, P. Sundararaghavan and U. Nandkeolyar, A newsvendor with priority classes and shortage cost. Am. J. Oper. Res. 5 (2015) 337-346.

[16] Z. Lin, Price promotion with reference price effects in supply chain. Transp. Res. Part E: Logistics Transp. Rev. 85 (2016) $52-68$.

[17] B. Liu, S. Ma, X. Guan and L. Xiao, Timing of sales commitment in a supply chain with manufacturer-quality and retailer-effort induced demand. Int. J. Prod. Econ. 195 (2018) 249-258.

[18] Q. Lu and S. Moorthy, Coupons versus rebates. Marketing Sci. 26 (2007) 67-82.

[19] M. Nouri, S.M. Hosseini-Motlagh, M. Nematollahi and B.R. Sarker, Coordinating manufacturer's innovation and retailer's promotion and replenishment using a compensation-based wholesale price contract. Int. J. Prod. Econ. 198 (2018) 11-24.

[20] S. Osman, B.C.Y. Fah and Y.S. Foon, Simulation of sales promotions towards buying behavior among university students. Int. J. Marketing Stud. 3 (2011) 78-88.

[21] I. Osuna, J. Gonzalez and M. Capizzani, Which categories and brands to promote with targeted coupons to reward and to develop customers in supermarkets. J. Retailing 92 (2016) 236-251.

[22] B. Pal, S.S. Sana and K. Chaudhuri, Two-echelon manufacturer-retailer supply chain strategies with price, quality, and promotional effort sensitive demand. Int. Trans. Oper. Res. 22 (2015) 1071-1095.

[23] N. Pakhira, M.K. Maiti and M. Maiti, Uncertain multi-item supply chain with two level trade credit under promotional cost sharing. Comput. Ind. Eng. 118 (2018) 451-463.

[24] R. Reddy, A quick guide to measuring trade promotion effectiveness \& ROI. Available from: https://acuvate.com/blog/ quick-guide-measuring-trade-promotion-effectiveness-roi/ (2018).

[25] S.S. Sana, Optimal production lot size and reorder point of a two-stage supply chain while random demand is sensitive with sales teams' initiatives. Int. J. Syst. Sci. 47 (2016) 450-465.

[26] B. Shen and Q.Y. Li, Impacts of returning unsold products in retail outsourcing fashion supply chain: a sustainability analysis. Sustainability 7 (2015) 1172-1185.

[27] S.P. Sigue, Consumer and retailer promotions: Who is better off? J. Retailing 84 (2008) 449-460.

[28] Y.Q. Su and J. Geunes, Multi-period price promotions in a single-supplier, multi-retailer supply chain under asymmetric demand information. Ann. Oper. Res. 211 (2013) 447-472.

[29] Y.C. Tsao and J.C. Lu, Trade promotion policies in manufacturer-retailer supply chains. Transp. Res. Part E: Logistics Transp. Rev. 96 (2016) 20-39.

[30] Y.C. Tsao and G.J. Sheen, Effects of promotion cost sharing policy with the sales learning curve on supply chain coordination. Comput. Oper. Res. 39 (2012) 1872-1878.

[31] R. Venkatesan and P.W. Farris, Measuring and managing returns from retailer-customized coupon campaigns. J. Marketing 76 (2012) $76-94$.

[32] J. Wu, Z.X. Chen and X. Ji, Sustainable trade promotion decisions under demand disruption in manufacturer-retailer supply chains. Ann. Oper. Res. (2018) 1-29.

[33] S.L. Yang, C.L. Munson, B.T. Chen and C.M. Shi, Coordinating contracts for supply chains that market with mail-in rebates and retailer promotions. J. Oper. Res. Soc. 66 (2015) 2025-2036.

[34] L. Yang, G. Wang and C.X. Ke, Remanufacturing and promotion in dual-channel supply chains under cap-and-trade regulation. J. Cleaner Prod. 204 (2018) 939-957.

[35] H. Yuan, M.I. Gomez and V.R. Rao, Trade promotion decisions under demand uncertainty: a market experiment approach. Manage. Sci. 59 (2013) 1709-1724. 